\title{
Application of built-in adjuvants for epitope-based vaccines
}

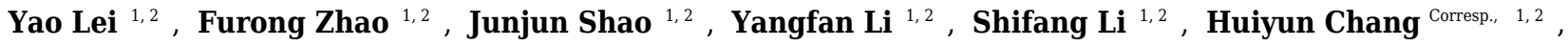 \\ Yongguang Zhang Corresp. 1,2 \\ ${ }^{1}$ State Key Laboratory of Veterinary Etiological Biology, OIE/National Foot-and-Mouth Disease Reference Laboratory, Lanzhou Veterinary Research \\ Institute,Chinese Academy of Agricultural Sciences, Lanzhou, China \\ 2 Jiangsu Co-innovation Center for Prevention and Control of Important Animal Infectious Diseases and Zoonoses, Yangzhou, China \\ Corresponding Authors: Huiyun Chang, Yongguang Zhang \\ Email address: changhuiyun@caas.cn, zhangyongguang@caas.cn
}

Several studies have shown that epitope vaccines exhibit substantial advantages over conventional vaccines. However, epitope vaccines are associated with limited immunity, which can be overcome by conjugating antigenic epitopes with built-in adjuvants (e.g., some carrier proteins or new biomaterials) with special properties, including immunologic specificity, good biosecurity and biocompatibility, and the ability to vastly improve the immune response of epitope vaccines. When designing epitope vaccines, the following types of built-in adjuvants are typically considered: 1 ) pattern recognition receptor (PRR) ligands (i.e., toll-like receptors [TLRs]); 2) virus-like particle (VLP) carrier platforms; 3) bacterial toxin proteins; and 4) novel potential delivery systems (e.g., self-assembled peptide nanoparticles [SAPNs], lipid core peptides [LCPS], and polymeric or inorganic nanoparticles). This review primarily discusses the current and prospective applications of these built-in adjuvants (i.e., biological carriers) to provide some references for the future design of epitope-based vaccines. 


\section{Application of built-in adjuvants for epitope-based vaccines}

2 Yao Lei ${ }^{1,2}$, Furong Zhao ${ }^{1,2}$, Junjun Shao ${ }^{1,2}$, Yangfan $\mathrm{Li}^{1,2}$, Shifang $\mathrm{Li}^{1,2}$, Huiyun Chang ${ }^{1,2^{*}}$, Yongguang Zhang ${ }^{1,2^{*}}$

1. State Key Laboratory of Veterinary Etiological Biology, OIE/National Foot-and-Mouth Disease

Reference Laboratory, Lanzhou Veterinary Research Institute, Chinese Academy of Agricultural

6 Sciences, Lanzhou, China.

2. Jiangsu Co-innovation Center for Prevention and Control of Important Animal Infectious

Diseases and Zoonoses, Yangzhou, China.

$9 *$ Corresponding authors.

Address: Stake Key Laboratory of Veterinary Etiological Biology, National

Foot-and-Mouth Diseases Reference Laboratory, Lanzhou Veterinary Research

Institute, Chinese Academy of Agricultural Sciences, Lanzhou, China 
ABSTRACT

Several studies have shown that epitope vaccines exhibit substantial advantages over conventional vaccines. However, epitope vaccines are associated with limited immunity, which can be overcome by conjugating antigenic epitopes with built-in adjuvants (e.g., some carrier proteins or new biomaterials) with special properties, including immunologic specificity, good biosecurity and biocompatibility, and the ability to vastly improve the immune response of epitope vaccines. When designing epitope vaccines, the following types of built-in adjuvants are typically considered: 1) pattern recognition receptor (PRR) ligands (i.e., toll-like receptors [TLRs]); 2) virus-like particle (VLP) carrier platforms; 3) bacterial toxin proteins; and 4) novel potential delivery systems (e.g., self-assembled peptide nanoparticles [SAPNs], lipid core peptides [LCPs], and polymeric or inorganic nanoparticles). This review primarily discusses the current and prospective applications of these built-in adjuvants (i.e., biological carriers) to provide some references for the future design of epitope-based vaccines. 


\section{INTRODUCTION}

46

Vaccination is a major preventive measure designed to establish specific immune defenses (i.e., antibody or cellular immunity) to protect individuals from infectious diseases. In 1796, the British rural doctor, Edward Jenner, conducted a scientific study on the prevention of smallpox in humans and demonstrated that vaccination with vaccinia virus could prevent smallpox, from which the terms vaccinology and immunology originated (Negahdaripour et al., 2017b). Traditional vaccines typically include inactivated or attenuated vaccines derived by reducing the virulence of the pathogen by physical or chemical methods (Skwarczynski \& Toth, 2011a; Karch \& Burkhard, 2016). Due to the continuous progress of science and technology (i.e., immunology and molecular biology), subunit vaccines based on short, specific pathogen fragments have undergone increased development to compensate for the shortcomings of traditional vaccines, including low biosafety (reversion to virulence), inefficient cultivation of pathogens, and the occurrence of allergies and autoimmunity (Skwarczynski \& Toth, 2014). Moreover, epitope-based vaccines play an important role in current vaccine research and exhibit several advantages over conventional vaccines, including high specificity, good safety, ease of production and storage, and stability. As a result of these advantages, epitope-based vaccines have become an area of growing interest in the field of vaccine research (Skwarczynski \& Toth, 2014; Hajighahramani et al., 2017; Nezafat et al., 2017; Nezafat et al., 2016). 
receptors expressed on the immune cells to identify antigen epitopes, and they do not generate a strong immune response to pathogens. An epitope-based vaccine with a reasonable design is composed of epitope peptide/s, a delivery system, and an adjuvant (Rueckert \& Guzman, 2012).

For multi-epitope vaccines, since the traditional carriers and adjuvants are associated with poor efficacy, vaccine designs with built-in adjuvants have been proposed. Therefore, a built-in adjuvant exhibiting both the functions of a transmission system and a traditional adjuvant, is constructed within the vaccine to improve the immunogenicity of epitope peptides by stimulating the innate immune response required for an adaptive immune response. To achieve this goal, the epitopes are regularly fused with adjuvant proteins (e.g., toll-like receptor [TLR] ligands and proteins that can spontaneously assemble into virus-like particles [VLPs]) or displayed on the surface of some particular biomaterials (e.g., liposomes, gold nanoparticles, and poly(lactic-coglycolic acid) [PLGA]) and the immunogenicity of the epitopes are significantly increased by this immune complex (Chen et al., 2017; Rueda et al., 2017; Kitaoka et al., 2017; Karuturi et al., 2017). This review primarily introduces the methods for applying built-in adjuvants in the design of epitope-based vaccines, including a few new delivery systems (e.g., dendrimers, self-assembled peptide nanoparticles [SAPNs], and hyperbranched polyglycerol [hbPG]) (Busseron et al., 2013; Glaffig et al., 2015; Indelicato et al., 2017).

\section{SURVEY METHODOLOGY}

In this paper, we reviewed articles related to the built-in adjuvants of epitope-based vaccines. All references in this review paper were retrieved using search engines, such as PubMed, Google Scholar. Keywords, including epitope vaccine, built-in adjuvants, biological carriers, and 
nanoparticles were used to search for relevant references.

\section{MAJOR IMMUNOLOGICAL CONCEPTS OF EPITOPE-BASED SUBUNIT}

\section{VACCINES}

Epitope-based subunit vaccines are typically composed of multiple epitopes derived from one or more pathogenic microorganisms (Azmi et al., 2014; Nezafat et al., 2017). These epitopes are generally composed of B cell epitopes, cytotoxic T cell (CTL) epitopes, and helper T cell (Th) epitopes. B cells identify thymus-dependent antigen (TD-Ag) through B-cell receptors (BCRs) expressed on their surface. The activation of B cells and the transfer of signals following activation requires two signals: 1) the BCR-specific receptor directly identifies B cell epitopes of the pathogen; and 2) the interaction between multiple co-stimulators on the surface of Th cells and B cells. In addition, activated $\mathrm{B}$ cells expressing a variety of cytokine receptors can proliferate in response to cytokines secreted by activated Th cells. The interaction between the specific $\mathrm{T}$ cell receptor (TCR) and the antigen peptide-major histocompatibility complex (pMHC) is known as antigen recognition, which is the first signal required for $\mathrm{T}$ cell activation. The interaction between many of the co-stimulatory molecules expressed on the surface of $\mathrm{T}$ cells and antigen presentation cells (APCs) (e.g., dendritic cells [DCs]) facilitates the complete activation of T cells. Activated Th1 cells secrete a variety of cytokines (e.g., IL-2, TNF- $\beta$, and IFN- $\gamma$ ) some of which (e.g., IL-2) induce non-professional or professional APCs to express co-stimulatory molecules that provide the second signal for the activation of CTLs (Moyle \& Toth, 2013; Skwarczynski \& Toth, 2014). These cytokines can also promote the activation and proliferation of Th1, Th2, CTL, and natural killer (NK) cells, and expand the cellular immune response. Th2 cells further promote the 
106

107

108

109

110

111

112

113

114

115

116

117

118

119

120

121

122

123

124

125 126

proliferation and differentiation of B cells and assist the humoral immune response by producing cytokines (e.g., IL-4, IL-5, IL-10, and IL-13) and establishing CD40-CD40L connections with B cells (Fig. 1). However, the individual specific epitopes of pathogenic microorganisms are often unable to induce adequate CTL and antibody responses due to a lack of appropriately activated Th cells and pathogen-derived molecules. Therefore, when designing epitope-based vaccines, researchers typically concatenate antigen-specific B cell or CTL epitopes with Th-cell epitopes with appropriate flexible linkers (e.g., GPGPG and EAAK) (Wang et al., 2018; Wang et al., 2011;

Nezafat et al., 2015).

Innate immune cells (e.g., monocyte-macrophages and DCs) recognize different pathogens through pattern recognition receptors (PRRs). Their antigen-presenting and cytokine regulation effects initiate adaptive immune responses, influence the intensity and type of an adaptive immune response, and participate in the generation of immunological memory. In the design of epitopebased vaccines, researchers generally regard the application of built-in adjuvants as an important platform used to provide suitable Th-cell epitopes for specific pathogens or pathogen related molecular patterns (PAMPs) to activate the innate immune response. Thus, some molecular adjuvants or carriers with no infectious and toxic components can be used as built-in adjuvants to facilitate the presentation of pathogen epitopes to the immune system (Moyle \& Toth, 2013; Foged, 2011; Shirbaghaee \& Bolhassani, 2016).

\section{TOLL-LIKE RECEPTOR (TLR) AGONISTS AS BUILT-IN ADJUVANTS}

25 The development of immunotherapeutic vaccines based on $\mathrm{T}$ cell immune responses is essential for the prevention and control of cancer and viral diseases. To achieve this goal, researchers must 
127 identify a built-in adjuvant that can stimulate strong Th1 immune responses (Felzmann et al., 128 2002). One of the strategies for designing epitope-based vaccines is to use TLR ligands as 129 adjuvants that can polarize CD4+ Th cells and induce CTL responses (van der Burg et al., 2006).

130 TLRs are a type of PRR that can both induce an innate immune response and activate the adaptive 131 immune system following PAMP activation (Allison et al., 2011). To date, researchers have 132 discovered 10 TLRs, termed TLR1 - TLR10 (Table 1). TLR ligands are expressed by different 133 microorganisms; for example, bacteria harbor a variety of TLR ligands, including TLR2 134 (macrophage-activating lipoprotein 2 [MALP2]); TLR4 (e.g., LPS, HSP, and HBHA), TLR5 (e.g., 135 flagellin), and TLR9 (CpG DNA) ligands (Zhu et al., 2010). The role of TLR10 is to inhibit rather 136 than activate the immune system, and its ligands are poorly understood (Jiang et al., 2016). The extracellular portion of the TLR is activated after binding to an appropriate ligand, and the conformational changes cause convergence of downstream molecules, which triggers associated signaling pathways and induces the up-regulation and activation of cytokines, chemokines, and other costimulatory factors (Dowling \& Dellacasagrande, 2016) (Fig. 2). Thus, TLR ligands are

141 promising candidates for the development of novel built-in vaccine adjuvants, which can enhance

142 the immunogenicity of epitope-based vaccines. According to the different biological 143 characteristics of various TLRs, appropriate PAMPs are often selected as the molecular binding 144 proteins of epitope peptides to be used as immune adjuvants (Basto \& Leitao, 2014). In this review, 145 several TLR ligands that are often used as built-in adjuvants for epitope vaccines are introduced.

\section{Lipopeptides}

As a lipopeptide derived from mycoplasma and a potential agonist of TLR2/6 heterodimers in DCs 
148 (Takeda et al., 2018), macrophage-activating lipopeptide-2 (MALP-2) is the most widely studied

149 TLR2 adjuvant and has attracted great interest as a novel and efficient built-in adjuvant for vaccines against infectious diseases (McDonald et al., 2014; Muhlradt et al., 1997). MALP-2 has been used in phase I and II trials involving pancreatic cancer patients (Schmidt et al., 2007). McDonald et al. constructed a variety of self-adjuvating MUC1-MALP-2 conjugate vaccine candidates and demonstrated that the vaccine candidates could induce a high level of humoral immunity without the participation of an external adjuvant and Th epitopes in animal models (McDonald et al., 2014). Fibroblast stimulating lipopeptide-1 (FSL-1; Pam2CGDPKHPKSF) and synthetic lipopeptide, Pam2CSK4, derived from the LP44 lipoprotein of Mycoplasma salivarium can activate macrophages as a TLR2/TLR6 ligand (Kurkjian et al., 2017; Liu et al., 2016). Liu et al. used FSL-1 as a built-in adjuvant and synthesized a new type of self-adjuvating (glyco) lipopeptide cancer vaccine (Liu et al., 2016). Recently, the TLR2/6 ligand, Pam2CSK4, was used as a Th2 polarizing adjuvant in the study of Leishmania major and Brugia malayi murine vaccines (Halliday et al., 2016). In addition, Pam2CSK4 is also used as an adjuvant for major outer membrane protein (MOMP) antigen of Chlamydia trachomatis to stimulate a robust immune response and induce effective protection against Chlamydia muridarum (Cheng et al., 2014). The Braun Escherichia coli lipoprotein is a prototype composed of the three acylated lipoproteins from the outer membrane of Gram-negative bacteria, and some of its synthetic lipopeptides act as TLR2 stimulators (e.g., Pam3CSK4) (Basto \& Leitao, 2014; Arai et al., 2018). Cai et al. designed and synthesized an HIV-1 glycopeptide immunogen containing a V3 glycan-dependent neutralizing epitope, a universal T helper epitope (P30), and a lipopeptide (Pam3CSK4). After administering 
169 the glycopeptide immunogen to rabbits without any additional adjuvants, a glycan-dependent 170 antibody can be produced in a short period of time, and the induced serum antibodies can recognize 171 a wide-range of HIV-1 gp120s across different clades (Cai et al., 2017). Pam2Cys and Pam3Cys 172 are also molecular adjuvants used in vaccines (Zaman \& Toth, 2013; McDonald et al., 2015; Nalla

et al., 2015) (Table 2; Fig.3). Synthetic lipopeptides and their analogues play an important role in the study of built-in adjuvants for epitope-based vaccines. However, compared with mature protein carriers for conjugated vaccines, TLR ligands (e.g., lipopeptides and monophosphoryl lipidA (MPLA) derivatives) are still in their early stages as potential vaccine carriers (Li \& Guo, 2018). However, since their interaction with TLRs has been thoroughly studied and understood, the prospective development of epitope-based vaccines using TLR ligands as built-in adjuvants is foreseeable. At present, one of the major challenges is obtaining a sufficient number of vaccines for clinical research since the structure of these lipopeptides, as well as their synthesis and binding to target antigens is highly complex. Semi-total and aminoalkyl glucosaminide 4-phosphates (AGPs) synthesis are important methods that can be used to solve this problem (Li \& Guo, 2018; Persing et al., 2002). AGPs have a less-complex structure that allows for synthesis to be easier, more efficient, and elicit immunostimulatory activity in preclinical studies. For example, a Hepatitis B vaccine based on AGP has been approved for use in Argentina (Dupont et al., 2006). A second challenge is how to make full use of all aspects of the multicomponent vaccine structure through reasonable considerations in vaccine design, which can be optimized through structureactivity relationship (SAR) analysis and molecular modeling (Jin et al., 2007).

\section{Heat shock proteins (HSPs)}


190

191

192

193

Heat shock proteins (HSPs) are a type of cellular companion protein produced by biological cells that are stimulated by environmental stressors and can be divided into several families, each of which is composed of different members (Juwono \& Martinus, 2016; Craig, 2018; Pearl et al., 2008; Tang et al., 2005; Bolhassani \& Rafati, 2008) (Table 3). HSPs can be internalized by APCs through receptor-mediated endocytosis and can also promote the activity of some cytokines, chemokines, and co-stimulatory molecules through the NF- $\mathrm{kB}$ signaling pathway, since HSPs are the molecular chaperones of the antigen epitopes in the APC-MHC I delivery pathway (Robert, 2003; Zachova et al., 2016). HSPs affect the immune system in different ways because they can act as carriers of antigens, molecular chaperones, and ligands for related receptors (e.g., TLR4) (Moyle, 2017). Among the HSPs, HSP60 obtained from Gram-negative bacteria has the ability to stimulate cells of both the innate and acquired immune system, functions as a linker between immune cells, and coordinates immunological activities. Therefore, HSP60 appears to be a promising potential component of subunit vaccines designed to provide protection from infections with Gram-negative bacteria (Bajzert et al., 2018). In addition, some researchers have confirmed murine HSP110 (mHSP110) to be a biological adjuvant that significantly enhances the immune response of $\mathrm{C} 57 \mathrm{BL} / 6$ mice to the $\mathrm{E}_{49-57}$ or $\mathrm{E}_{11-20}$ epitopes of h-2d restricted human papillomavirus (HPV) (Ding et al., 2013). In addition, the Gp96-peptide complex is considered to be a highly effective stimulator of MHC I-mediated antigen presentation; this strategy makes full use of the built-in adjuvant function and antigen transfer ability of Gp96 to induce cytotoxic immunity against widespread viral or tumor antigens (Strbo et al., 2013).

Mycobacterial HSP70 (mHSP70) is widely used as an intramolecular adjuvant for epitope- 
211 based vaccines, and the carboxyl terminal polypeptide binding area (HSP70 aa $359-610$ ) of

212 mHSP70 has a stimulating epitope that can combine with the CD40 receptor to stimulate the

213 production of Th1-polarizing cytokines (e.g., IL-12, TNF- $\alpha$, and NO) to induce DC maturation

214 (Wang et al., 2002; Suzue et al., 1997; Suzue \& Young, 1996). Compared with the T cell epitopes

215 of other proteins, the HSP70 T cell epitope can be efficiently processed by APCs, so that the

216 polypeptide binding region of HSP70 has higher affinity with MHC molecules (Basu et al., 2001;

217 Castellino et al., 2000). The single HSP70, which does not fuse with other exogenous epitopes,

218 only induces a very weak cellular and humoral immune response. Some studies have shown that

219 removing the amino end of HSP70 (ATPase domain) and retaining only its carboxyl end

220 (polypeptide binding region) as an antigen can produce a large amount of IL-12, TNF- $\alpha$, NO, and

221 chemokines (Fu et al., 2013). In contrast, neither the ATPase domain nor native HSP70 can induce

222 such a powerful immune response (Cheng et al., 2014; Li et al., 2006; Ge et al., 2006). For

223 example, the fusion of the hantavirus (HTNV) glycoprotein (GP) and nucleocapsid protein (NP)

224 with the carboxyl end of HSP70 can induce a more specific immune response (Cheng et al., 2014).

225 The major antigenic segment of the Japanese encephalitis virus E protein can fuse with the amino

226 terminus of the peptide binding domain of HSP70, which can induce a more effective immune

227 response than the major antigenic segment of the E protein alone (Ge et al., 2006). HSP70s and

228 HSP90s have been also found to act as carriers of tumor-derived peptides, adjuvants for antigen

229 presentation, and can target the innate immune system by inducing anti-tumor immune responses

230 (Shevtsov \& Multhoff, 2016).

231 Heparin-binding hemagglutinin (HBHA) 
232 With regards to Mycobacterium (M.) tuberculosis antigens, several Mycobacterium lipid and

233 glycolipid antigens (e.g., mycolic acid, lipoarabinomannan, glucose monomycolate [GMM]) can

234 be recognized by specific T cells by the CD1 antigen-presentation pathway in humans, suggesting

235 the possible application of $M$. tuberculosis lipid molecules in subunit vaccine preparation (Moody

236 et al., 2000). Dascher et al. developed a vaccine which included lipids from M. tuberculosis that

237 were incorporated into liposomes with an adjuvant; the studies using a guinea pig aerosol

238 tuberculosis challenge model demonstrated that lipid antigens play an important role in the

239 immune response to tuberculosis infection, potentially through the production of CD1- restricted

240 T cells (Dascher et al., 2003). In addition, the M. tuberculosis 6-kilodalton early secreted antigenic

241 target protein (ESAT-6) is considered to be an important mediator in mycobacterial virulence, has

242 strong antigenicity, and can induce a protective Th1 immune response against $M$. tuberculosis

243 (Pandey et al., 2018). Khader et al. vaccinated mice with an ESAT-6 peptide (amino acids $1-20$

244 of ESAT-6) in an adjuvant composed of monophosphoryl lipid A (MPL), trehalose

245 dicorynomycolate (TDM), and dimethyl dioctadecylammonium bromide (DDA). The vaccination

246 was found to induce antigen-specific $\mathrm{T}$ cells that produced IFN- $\gamma$, $\mathrm{T}$ cells that persisted in the

247 central lymphoid organs, and antigen-specific IL-17-producing T cells that persisted in the lung

248 (Khader et al., 2007). Recently, heparin-binding hemagglutinin (HBHA), a component of

249 Mycobacterium (M.) tuberculosis, has been closely investigated for its strong immune potential,

250 which can stimulate the migration of DCs and promote the expression of a variety of surface

251 molecules (e.g., CD40, CD80, and CD86), MHC I and MHC II molecules, as well as inflammatory

252 cytokines (e.g., IL-6, IL-12, IL-1 $\beta$, and TNF- $\alpha$ ) in a TLR4-dependent manner (Jung et al., 2011; 
253 Eraghi et al., 2017). For example, HBHA can induce immunological protection against $M$. 254 tuberculosis by stimulating the production of IFN- $\gamma$, IL-2, and IL-17-coexpressing CD4+ T cells 255 (Fukui et al., 2015). As an effective immune adjuvant, HBHA can induce a strong Th1 cell immune response and plays an important role in the research of multi-epitope vaccines for immunotherapy 257 (i.e., tumor vaccines). It has also been reported that the amino acid sequence of the epitope for the MAP1611 immunization region of the Mycobacterium avium subsp., paratuberculosis (MAP), is connected to the conservative amino acid sequence of HBHA. In addition, this recombinant subunit vaccine exhibited good immunogenicity and was identified to have a no allergenicity as predicted by employing a hybrid approach using the AlgPred program. (Rana et al., 2014; Rana \& Akhter, 2016). Some researchers have designed a multi-epitope vaccine that includes CTL epitopes of Wilms tumor-1 (WT-1) and HPV E7 antigens, helper T lymphocyte (HTL) epitopes of the tetanus toxin fragment $\mathrm{C}$ (TTFrC) and HLA PADRE, and HBHA as the intramolecular adjuvant of epitope-based vaccines and is connected with appropriate linkers to enhance the effect of this recombinant multiple-epitope vaccine against cancer (Nezafat et al., 2014; Nezafat et al., 2015). As a built-in adjuvant with a powerful immune enhancement effect, HBHA is rarely used in epitope vaccine research and is worthy of further study in the development of antiviral and cancer epitope-based vaccines.

\section{Bacterial flagellin}

Flagellins are TLR5 and NOD receptor ligands that can activate both innate and acquired immune cells (Huleatt et al., 2008; Wang et al., 2014; Hajam et al., 2017). Both the N- and C- terminals of 
274 the portion between the $\mathrm{N}$ - and C-terminals comprises a highly variable flagellin antigen region

275 (Murthy et al., 2004). It has been found that deletion of part of the highly variable region of 276 flagellin disables the ability of the host to produce antibodies against bacterial flagellum but does 277 not affect its adjuvant activity (Deng et al., 2017). Therefore, researchers typically replace this 278 region with exogenous antigen epitopes (e.g., the HPV prophylactic peptide vaccine) (Nempont et al., 2008; Negahdaripour et al., 2017a). For example, replacing the FliC variable region with the

M2e protein of influenza A does not obstruct TLR signaling pathways (Smith et al., 2003; Deng et al., 2017). A truncated flagellin ( $\mathrm{tFL}$ ) with deletion of the hypervariable regions was used as a carrier by chemical conjugation with a malaria antigen M.RCAg-1 (M312), and compared with the physical mixture of M312 and tFL, the conjugates M312-PEG-tFL elicited higher M312specific antibody titers (Guo et al., 2018). In addition, two HPV epitopes and some universal Th epitopes have been linked to the different flagellin positions via different linkers, and the optimal construction of a multiepitope vaccine was screened using protein structure analysis, modeling, optimization, and an evaluation of immunogenicity (Negahdaripour et al., 2017c). In addition, four copies of the ectodomain of matrix protein 2 (f4M2e) of the influenza A virus, H1, HA2 domain (fHApr8), or H3 HA2 domain (fHAaichi) were used to replace the high immunogenicity region of flagellin, and the fusion proteins were crosslinked with propionate (DTSSP) to form protein nanoparticles, thereby retaining the agonist activity of FliC to TLR5, and ability to assist the epitope protein in stimulating the immune response against influenza A virus (Deng et al., 2017).

The combination of flagellin with multiple copies of HPV L2 neutralization epitopes have demonstrated a strong broad spectrum anti-HPV effect without the participation of other adjuvants, 
295

296

297

298

299

300

301

302

303

304

305

306

307

308

309

310

311

312

313

314

315

thus demonstrating a significant advantage of this strategy in enhancing the cross-protection of the HPV vaccine (Kalnin et al., 2014; Gambhira et al., 2007; Kalnin et al., 2017). In addition, Ajamian et al. found that inserting the HIV gp41 $607-683$ (MPER) into a flagellin-based scaffold could significantly enhance the immunogenicity of gp4 ${ }_{607-683}$ in a TLR5-dependent manner and induce strong humoral responses specific to MPER in a mouse model (Ajamian et al., 2018). Various flagellin antigen fusion proteins have been studied in human clinical trials. Furthermore, flagellin is also commonly used as an antigen skeleton of self-assembled peptides nanoparticle (SAPN)based vaccines (El et al., 2017), for which the associated content is described below.

\section{Outer membrane vesicles (OMVs)}

Outer membrane vesicles (OMVs) are naturally secreted on the surface of most gram-negative bacteria, and the vesicle membrane typically consists of lipopolysaccharide (LPS), glycerophospholipids, and outer membrane proteins (OMPs) (Tan et al., 2018). Due to their intact outer membrane and periplasmic contents, OMVs possess good intrinsic stimulation ability and strong immunoreactivity, which can induce strong humoral and cellular immune responses. In addition to research focused on the possibility of using OMVs as candidate antigens for vaccine development, there is growing interest in the application of OMVs as a self-adjuvant for immunostimulatory molecules. This function is mediated by the interaction between the OMVassociated PAMPs and the TLRs expressed on the surface of APCs, thus enhancing the immune response to exogenous antigens (Gnopo et al., 2017). OMVs can also even be used as a mucosal transporter to transport antigens to the mucosal barriers (Jang et al., 2004). In addition, designed glycoengineered OMVs (geOMVs), which can display the O-antigen and surface glycans from 
316

317

318

319

320

321

322

323

324

325

326

327

328

329

330

331

332

333

334

335

336

different bacteria could be used as bacterial vaccine platforms to prevent bacterial infections (Valguarnera \& Feldman, 2017). In addition, plasmids can be transported into OMVs to further modify the intracavity content, including LPS functionality and attenuate toxicity (Tan et al., 2018). Hekmat et al. developed a novel HCV therapeutic vaccine candidate, rC/N-NMB OMVs, formulated as a targeted synthesized recombinant fusion protein consisting of a truncated core and $\mathrm{NS} 3(\mathrm{rC} / \mathrm{N})$ of $\mathrm{HCV}$ as a bipartite antigen accompanied by Neisseria meningitidis serogroup B OMVs (NMB OMVs), has the ability to induce Th1, Th2, and Th17 immune responses. Compared with MF59 and Freund adjuvant, NMB OMVs can significantly increase the level of Th1 immune responses (Hekmat et al., 2018). Liu et al. have demonstrated OMVs from flagellin-deficient S.Typhimurium can serve as an adjuvant when combined with OMPs from different Salmonella serotypes, and enhances the cross-protection capacity of this combined vaccine (Liu et al., 2018). Additionally, novel vaccine adjuvant OMVs have been reported, which can serve as delivery carriers to improve vaccine safety and protective efficacy. ClyA is a $34 \mathrm{kDa}$ pore-forming toxin enriched on OMVs, for which exogenous antigens are fused at the $\mathrm{C}$ terminus of ClyA to produce ClyA-antigen fusion proteins on OMVs (Kim et al., 2008). Chen et al. demonstrated that rOMVs carrying ClyA-GFP fusion proteins could induce a high level of anti-GFP IgG titers in mice, which was similar to that of GFP adjuvanted with alum (Chen et al., 2010). Rappazzo et al. immunized mice with ClyA-M2e4xHet OMVs displaying an influenza-derived antigen, M2e4xHet, which was associated with 100\% survival following subsequent influenza challenge (Rappazzo et al., 2016). In addition to ClyA, other prospective proteins also have the potential to display an antigen of interest, such as the hemoglobin protease (Hbp) autotransporter platform (Daleke-Schermerhorn 
337 et al., 2014). Jong et al. introduced a mutation to preserve the integrity of Hbp to avoid cleavage

338 following translocation to the outer membrane (Jong et al., 2014). Kuipers et al. demonstrated that

339 rOMVs displaying the pneumococcal antigens, pneumococcal surface protein A (PspA) and

340 pneumolysin (Ply), by the Hbp system could prevent pneumococcal colonization (Kuipers et al.,

341 2015). Although some obstacles to the development of OMV adjuvants remain (e.g., large number

342 of clinical and preclinical assessments, and limited knowledge of the OMV manufacturing

343 process), we believe that the use of OMVs as an epitope-based vaccine delivery system would also

344 be of great value in controlling all types of pathogen infections due to their comprehensive immune

345 potency, higher safety, and substantial mucosal delivery efficacy (Tan et al., 2018).

346 In addition, generalized modules for membrane antigens (GMMA) as an outer membrane vesicle technology are outer membrane particles consisting of outer membrane lipids, OMPs, and soluble periplasmic components (Gerke et al., 2015). GMMA are derived from gram-negative bacteria (i.e., Salmonella and Shigella) which are genetically modified (deletion of the tolR gene) to enhance the associated advantages of being cost-effective with high-production yields. Further gene deletions (i.e., the late acyltransferases genes HtrB175 and MsbB) resulted in GMMA with penta-acylated LPS with no possibility of infection (Rossi et al., 2014). Due to the self-adjuvanting properties of GMMA that deliver innate immune signaling through PAMPs (i.e., TLR ligands), many studies have shown that GMMA vaccines can simultaneously deliver surface polysaccharides and OMPs to the immune system and display greater immunogenicity compared to glycoconjugate vaccines (Micoli et al., 2018; MacLennan et al., 2014). Moreover, it has been demonstrated that the GMMA technique can be used as a carrier to display the salmonella 
358

359

360

361

362

363

364

365

366

367

368

369

370

371

372

373

374

375

376

377

378

lipopolysaccharide O-antigen to the immune system. It is envisaged that GMMA could also be considered as a built-in adjuvant platform for epitope-based vaccines against pathogens other than gram-negative bacteria. More importantly, clinical trials (currently under way with Shigella sonnei GMMA vaccines) are required to further assess the safety and tolerance of this vaccine platform in humans.

\section{Salmonella porin}

Salmonella Typhi expresses a variety of porins. While the major S. Typhi OmpC and OmpF porins can be expressed constitutively, the expression of other porins (e.g., OmpS1 and OmpS2) is relatively low in vitro and during potential infection (Perez-Toledo et al., 2017). Both the major and minor S. Typhi porins can effectively activate the innate immune system through the TLR2 and TLR4 signaling pathways, resulting in the increased expression of costimulatory molecules and cytokines in DCs and B cells (Moreno-Eutimio et al., 2013; Cervantes-Barragan et al., 2009). Due to such immune-activating properties, some of these porins have been used as potential vaccine adjuvants. Pérez-Toledo et al. have shown that the S. Typhi porins, OmpC and OmpF, are multipurpose vaccine adjuvants, which can be used to polarize the $\mathrm{T}$ cell response towards a Th1/Th17 profile and enhance the antibody response generated towards T-dependent and Tindependent antigens with poor immunogenicity (Perez-Toledo et al., 2017). In addition, Leclerc et al. used malva mosaic virus (MaMV) nanoparticles as a vaccine platform to improve the stability of the M2e peptide of influenza A in conjunction with OmpC purified from Salmonella typhi as an adjuvant; their data demonstrate that OmpC increased the immune response to the M2e peptide and provided protection against a heterosubtypic influenza strain in a mouse model (Leclerc et al., 
379

380

2013). Moreover, Moreno-Eutimio et al. investigated the immunogenic and protective capacities of the OmpS1 and OmpS2 porins and determined that these porins can be potent inducers of the innate immune response, exhibiting adjuvant properties that can promote increased antibody titers and long-term antibody responses when co-immunized with antigens (Moreno-Eutimio et al., 2013).

\section{$\beta$-defensin}

$\beta$-defensins are antimicrobial peptides involved in the innate immune response of the host and are responsible for stimulating innate and adaptive immune responses by recruiting naïve $\mathrm{T}$ cells and immature DCs through interactions with corresponding immune receptors (e.g., CCR6 or TLRs) (Narula et al., 2018). Kim et al. have concluded that human $\beta$-defensin (HBD) 2 can induce the primary antiviral innate immune response and may also mediate the induction of antigen-specific immune response against a conjugated antigen (Kim et al., 2018). Using immunoinformatic methods, a multi-epitope vaccine for dengue was developed that included Tc and Th cell epitopes with $\beta$-defensin included as a molecular adjuvant at the N-terminal of the construct (Ali et al., 2017). Similarly, researchers developed an anti-chikungunya multi-epitope vaccine that included $\mathrm{B}$ cell and T cell-binding epitopes and IFN- $\gamma$ inducing epitopes with $\beta$-defensin added as a builtin adjuvant (Narula et al., 2018).

\section{VIRUS-LIKE PARTICLES (VLPs) AS BUILT-IN ADJUVANT}

\section{PLATFORMS}

\section{Hepatitis B virus core antigen ( $\mathrm{HBcAg})$}

HBcAg can act both as a Th cell-dependent or Th cell-independent antigen (Roose et al., 2013), 
400

401

402

403

404

405

406

407

408

409

410

411

412

413

414

415

416

417

418

419

420

and the Th-priming effects of $\mathrm{HBcAg}$ can easily transfer the adaptive response to the inserted related epitopes (Milich et al., 1987). In addition, the nanoscale structure of HBcAg can be more effectively identified and processed by APCs (Lee et al., 2009; Ong et al., 2017). Therefore, $\mathrm{HBcAg}$ has been used as an vaccine carrier for several exogenous pathogens (e.g., hepatitis B, C, and $\mathrm{E}$ virus, influenza virus, foot-and-mouth disease virus, Human enterovirus 71, coxsackievirus A16, and Chlamydia trachomatis), and the immunogenicity of recombinant HBc-based virus like particle (VLP) vaccines against pathogens has also been verified in animal models (Dai et al., 2016; Su et al., 2013; Zheng et al., 2016; Chu et al., 2016; Zhu et al., 2016; Wu et al., 2017; Jiang et al., 2017). VLPs are the self-assembled structural proteins of most viruses and can stimulate the immune response in the absence of an adjuvant by exposing pathogen epitopes and simulating the structure of natural viruses (Plummer \& Manchester, 2011; Yang et al., 2016). In addition, VLPs can stimulate an innate immune response by activating PRRs (e.g., TLRs) (Shirbaghaee \& Bolhassani, 2016). In addition, the autoantigen molecules displayed by HBcAg VLPs can escape immune tolerance and produce specific auto-antibodies (Long et al., 2014). Due to these advantages, the $\mathrm{HBc}$ is often used as a powerful carrier protein and built-in adjuvant to display exogenous epitopes (Chen et al., 2017; Jiang et al., 2017; Roose et al., 2013; Liang et al., 2018). In general, researchers will insert pathogen epitopes into the HBcAg major immunogenic region (MIR; HBcAg aa $78-82$ in the spike tip of HBV), which does not affect the self-assembly of the fusion protein into VLP nanoparticles, to generate immune activation; therefore, antigen epitopes will be presented on the surface of the particles (Wang et al., 2017; Chen et al., 2017) (Fig. 4A). As the main insertion site of exogenous epitopes, MIR can significantly enhance the 
421 immunogenicity of such epitopes (Dai et al., 2016; Reynolds et al., 2015). Recently, Wu et al.

422 developed a novel vaccine against chickenpox and hand-foot-mouth disease (HFMD) by

423 constructing three VLPs with HBcAg used as a carrier protein, and epitopes derived from varicella-

424 zoster virus (VZV)-gE, EV71 (enterovirus71)-VP1, and EV71-VP2 were displayed by HBcAg .

425 This study also fully demonstrated the significant potential of $\mathrm{HBcAg}$ as a carrier protein for

426 epitope vaccines used in multivalent epitope vaccine research (Wu et al., 2017). The tandem core

427 (TC) contains two HBcAg molecules that are connected by the appropriate linker and has two

428 independent MIRs which can individually accommodate multiple exogenous antigens (Fig. 4B).

429 This VLP platform is associated with beneficial prospects for the development of multivalent

430 vaccines (Roose et al., 2013). Alejandro et al. inserted the four conserved antigenic regions of the

431 matrix protein 2 ectodomain and hemagglutinin stalk of an existing influenza A virus (IAV) into

432 the MIR region of TC, thereby constructing a VLP vaccine called Tandiflu1, which can induce the

433 production of cross-protective antibodies (Ramirez et al., 2018).

\section{Hepatitis B virus surface antigen (HBsAg)}

435 The tertiary structure of HBsAg can form a highly conserved hydrophilic loop. Additionally, it has

436 been reported that the existing immunity to HBsAg does not impede the immune response to

437 foreign epitopes carried by HBsAg particles, which is often used as a carrier to insert exogenous

438 antigens into the external hydrophilic loop or the end of the HBsAg N- or C-terminal (Bellier \&

439 Klatzmann, 2013). Czarnota et al. inserted a highly conserved epitope (amino acid residues 412 -

440 425) of the hepatitis C virus (HCV) E2 glycoprotein into the hydrophobic loop of HBsAg, and the

441 chimeric protein was then expressed in an unconventional Leishmania tarentolae expression 
442 system and independently assembled into VLPs, which demonstrated high immunogenicity and 443 induced cross-reactive antibodies against HCV (Czarnota et al., 2016). Wei et al. also used HBsAg 444 to display neutralizing HCV epitopes to obtain chimeric HCV-HBV VLPs as a novel strategy for 445 developing a bivalent prophylactic HCV-HBV epitope vaccine (Wei et al., 2018). The envelope 446 protein domain III (EDIII) of dengue viruses (DENV) contains good serotype-specificity and cross-reactive epitopes. Ramasamy et al. fused the EDIII of all four DENV serotypes with four copies of HBsAg and expressed the construct in the $P$. pastoris GS115 strain to obtain a tetravalent

VLP vaccine termed DSV4, which has a high immunogenicity and produces effective and persistent neutralizing antibodies against all four DENV serotypes in mice (Ramasamy et al., 451 2018).

\section{Phage-based VLPs}

The over-expression of the single-chain dimer coat proteins of MS2 and PP7 RNA phages in bacteria can spontaneously assemble into recombinant MS2 or PP7 VLPs containing 90 dimer copies and 90 exogenous epitopes. In addition, for the Q $\beta$ bacteriophage, 180 copies of singlechain dimer capsid proteins can spontaneously assemble into a VLP; thus, at least 180 exogenous epitopes can be displayed on the surface of a Q $\beta$ VLP (Basu et al., 2018). Recent reports have shown that the Q $\beta$ bacteriophage contains TLR ligands that can enhance Q $\beta$-VLP-induced T cellindependent and -dependent $\mathrm{Ab}$ reactions, including a germinal center $(\mathrm{GC})$ reaction via of TLR/MyD88 signaling in B cells (Tian et al., 2018). This VLP platform which contains no viral genome can be used in the future as a carrier system for the administration of safe vaccines against 
463 the envelope proteins of Zika virus on the surface of a highly immunogenic bacteriophage VLP 464 platform (MS2, PP7, and Q $\beta$ ), and evaluated the immunogenicity of these VLPs in mice (Basu et 465 al., 2018) Zhai et al. also displayed consensus peptides from HPV L2 and tandem HPV31/16L2 466 peptides on the surface of bacteriophage MS2 VLPs. These MS2-L2 VLPs can induce high 467 antibody titers in mice and are cost-effective vaccine candidates against HPV; however, HPV 468 vaccines with greater cross-protection should be further evaluated to prevent more types of HPV 469 (Zhai et al., 2017). Recently, Q $\beta$ VLPs have been applied as carriers for the development of carbohydrate-based anticancer vaccines (Sungsuwan et al., 2017). Additionally, researchers have developed a size-exclusion chromatography-based purification method for an VLP-based influenza A vaccine derived from the MS2 phage that displays an epitope from the extracellular domain of the influenza A virus matrix 2 protein. Moreover, the purification procedure provides an improved strategy for the future large-scale production of VLP-based epitope vaccines (Lagoutte et al., 2016).

Tobacco Mosaic Virus (TMV)

Tobacco mosaic virus (TMV) is a widely studied and identified filamentous plant virus. TMV

particles are hollow with tubular rods (300 nm length $\times 18 \mathrm{~nm}$ diameter) consisting of about 2130 coat protein (CP) subunits encase a single-stranded, plus-sense RNA genome (Culver, 2002). As an antigen carrier, TMV has two important functions: 1) due to the architecture and size of TMV, TMV carrying antigen epitopes is robustly and readily taken up by dendritic cells, leading to the activation of key surface markers (Smith et al., 2007); and 2) TMV also provides adjuvant effects, due to either repetitive antigen displayed on the surfaces of TMV or the presence of non-functional 
484 viral RNA that is important for inducing cellular-mediated immunity (Banik et al., 2015).

485 Kemnade et al. demonstrated that TMV is capable of boosting TMV-induced antigen-specific T 486 cell responses, but does not induce neutralizing self-immunity (Kemnade et al., 2014). In addition, 487 since TMV is not a human pathogen, it is intrinsically secure (Liu et al., 2013). These findings further confirm that TMV has great potential as an epitope-based vaccine vector. McCormick et al. fused well-characterized $\mathrm{T}$ cell epitopes that provide protection against tumor challenge in mice into a TMV coat protein and demonstrated that C57BL/6 mice inoculated with TMV displayed significantly improved protection against tumor challenge in both the EG.7-Ova and B16 melanoma models (McCormick et al., 2006). Moreover, Zhao et al. reported that when efficient copper (I)-catalyzed azide-alkyne cycloaddition reaction (CuAAC) was performed for the conjugation of the small molecule estriol (E3) onto TMV capsid, TMV can induce a strong and

long-term antibody response (Zhao et al., 2015). Furthermore, Banik et al. developed a multivalent subunit vaccine against tularemia using a TMV-based delivery platform and demonstrated TMV can serve as a suitable built-in adjuvant for multiple protective antigens of $F$. tularensis, as well as induce cell-mediated immune responses and long-lasting humoral immunity against tularemia

499 (Banik et al., 2015).

\section{Papaya mosaic virus (PapMV)}

As a member of the potexvirus family, papaya mosaic virus (PapMV) displays a flexible rod-like structure composed of 1,400 subunits of the viral coat protein $(\mathrm{CP})$ assembled around a positivestrand RNA (Lacasse et al., 2008). Since PapMV-based VLPs comprised of PapMV CPs 
505

506

as a vaccine adjuvant platform. Following phagocytosis, PapMV-based VLPs can reach the endosome of immune cells and release ssRNA, which engages and activates TLR7 (Therien et al., 2017). The direct fusion of antigenic peptides to the open reading frame (ORF) of the PapMV CP can lead to the formation of chimeric VLPs that can trigger a humoral or CTL response against the fused antigen (Bolduc et al., 2018). Additionally, Carignan et al. have shown that the fusion of a short M2e (sM2e) epitope (nine amino acids) to the N-terminus of the PapMV CP allows for the assembly of highly immunogenic VLPs. This group further demonstrated that an intramuscular injection of PapMV-sM2e VLPs is sufficient to induce a powerful anti-M2e humoral response that protects mice against subsequent challenge with influenza A (Carignan et al., 2015). Similarly, Bolduc et al. have developed a PapMV-based VLP vaccine candidate capable of inducing robust and broad protection against two different influenza A strains (H1N1 and H3N2) (Bolduc et al., 2018). Lacasse et al. have shown that PapMV VLPs carrying the H-2b-restricted dominant $\mathrm{p} 33$

CTL epitope from the lymphocytic choriomeningitis virus (LCMV) can induce DC maturation and cross-presentation of the p33 CTL epitope, which triggers a protective antiviral $\mathrm{T}$ cell response (Lacasse et al., 2008). Furthermore, Thérien et al. engineered a PapMV-based VLP platform with a SrtA receptor motif and allowed SrtA to attach to the long peptides of the VLPs. This approach was found to be more versatile than the fusion of only small peptides to the ORF of the PapMV CP. Therefore, PapMV nanoparticles with SrtA-conjugated peptide antigens may represent a promising tool in vaccine design against various diseases (Therien et al., 2017).

\section{KEYHOLE LIMPET HEMOCYANIN (KLH) AND BOVINE SERUM ALBUMIN (BSA)}

Keyhole limpet hemocyanin (KLH) and bovine serum albumin (BSA) are easily identified by the 
526

527

immune system as non-self components, which is useful for enhancing the immunogenicity of small antigens or a low antigen dose. KLH and BSA are easily processed APCs and can recruit Th cells to assist in antigen uptake (Mora et al., 2017). These characteristics of KLH and BSA have promoted their frequent use as epitope carrier proteins. For example, researchers have developed the novel epitope peptide vaccine, $\mathrm{A} \beta 3-10-\mathrm{KLH}$, by coupling the $\mathrm{B}$ cell epitope, $\mathrm{A} \beta 3-10$, from amyloid- $\beta$ peptide $(\mathrm{A} \beta)$ with $\mathrm{KLH}$, for the potential treatment and prevention of Alzheimer's disease (AD) (Ding et al., 2017; Ding et al., 2016). In another study, an anti-PCSK9 (proprotein convertase subtilisin/kexin type 9) peptide vaccine using KLH as the carrier protein was shown to produce long-lasting anti-PCSK9 antibodies and is considered to be the primary vaccine for the treatment of dyslipidemia in the future (Kawakami et al., 2018). In addition, a short peptide (UPK3A 65-84) from Uroplakin 3A (UPK3A) covalently coupled with KLH and CpG as adjuvant was found to be an immunotherapeutic vaccine for bladder cancer (Izgi et al., 2015). In addition, BSA is often used as a carrier protein for small antigens in glycoconjugate vaccines (Prasanphanich et al., 2015). For example, Cai et al. combined a synthesized MUC1 glycopeptide with BSA or three different T-helper cell epitopes of TTox and demonstrated a beneficial effect (Cai et al., 2013). Furthermore, the immune complex formed by coupling the synthetic trisaccharide Gal $\alpha(1,3) \mathrm{Gal} \beta(1,4) \mathrm{GlcNAc} \alpha$ of Trypanosoma cruzi with BSA as a carrier protein was reported to be a vaccine candidate for Chagas disease (ChD) (Schocker et al., 2016).

\section{BACTERIAL TOXIN PROTEINS}

\section{Heat-labile toxins (HLT) and cholera toxin (CT)}

Heat-labile toxins (HLTs) are produced by some enterotoxigenic Escherichia coli strains and can 
547 be fused with other antigenic proteins to function as an adjuvant (Da et al., 2011; Luiz et al., 2015;

548 Hu et al., 2014) (Table 4). HLTs and cholera toxins (CTs) are highly homologous, consisting of

549 five subunit-Bs and one subunit-A, and are members of the bacterial protein toxin AB5 family.

550 Subunit-A is a toxic subunit, noncovalently bound to the B pentamer and has ADP

551 ribosyltransferase activity, whereas subunit-B is a nontoxic receptor-binding subunit (Lencer et

552 al., 1999). Generally, non-toxic HLTs (e.g., subunit-B and mutant forms of HLT) also act as

553 immune adjuvants to activate DCs, B cells, and T cells, regulate epitope specificity, and improve

554 the immune response (Batista et al., 2014; Rodrigues et al., 2011). The fusion of the HLT B subunit

555 (HLTB) with the linear B cell epitope of the outer membrane protein (OmpC) of Aeromonas

556 hydrophila can stimulate the production of neutralizing antibodies against this linear epitope and

557 generate a Th2 type mixed auxiliary T cell immune response (Sharma et al., 2017). The two

558 epitopes of the Zairian Ebola virus GP1 protein, which can be recognized by neutralizing

559 antibodies, were coupled with HLTB protein to form recombinant antigen HLTB-EBOV

560 expressed in plant tissues, and immunizing mice with the recombinant antigen presented by the

561 plant induced a higher level of IgA and IgG responses (Rios-Huerta et al., 2017). The CT subunit-B

562 (CTB) can be used as a powerful adjuvant to generate mucosal immunity due to its strong affinity

563 to the GM1 ganglioside receptor which is primarily located on mucosal epithelial cells (i.e., M

564 cells) (Pinkhasov et al., 2010). The multivalent epitope-based vaccine against $H$. pylori, CWAE,

565 and an anti-atherosclerosis multi-epitope vaccine have been developed using CTB as

566 intramolecular adjuvant (Tourani et al., 2017; Guo et al., 2017).

\section{Diphtheria toxin (DTT)}


568 The carrier protein cross-reacting material 197 (CRM197) is an inactivated and non-toxic form of

569 diphtheria toxin (DTT) created using an enzymatic reaction, and has been successfully applied in 570 many vaccines against infectious diseases because it can effectively combine and present peptides 571 (Caro-Aguilar et al., 2013) (Table 4). Moreover, CRM can rapidly activate $\mathrm{CD}^{+} \mathrm{T}$ cells by generating a multitude of Th1 and Th2 cytokines, thereby promoting the proliferation of B cells and regulating the level of antibody production (Kamboj et al., 2001). Several short B cell epitopes (P4, P6, and P7) on the Her-2/neu protein were combined with the polyepitope peptide, P467, using CRM197 as a carrier protein to conjugate with this complex epitope, demonstrated a strong anti-tumor response (Tobias et al., 2017). The function of DTT is to assist the enzyme active region (C-domain) in passing through the endocytosis membrane, and there are no associated risks when the transmembrane domain of DTT is used as the protein carrier for exogenous antigen (Ladokhin, 2013; Malito et al., 2012).Xu et al. developed a VEGF (vascular endothelial growth factor)-based antigen DTT-VEGF consisting of the receptor-binding domain of VEGF and DTT stimulated neutralizing antibody response and induced type 1 immune response as well as anti-tumor CTLs in mice, and their data demonstrated that DTT is an effective antigen carrier to break immune selftolerance and DTT-VEGF has potential to be used a promising cancer vaccine (Xu et al., 2017). In addition, DTT contains four Th cell epitopes (aa $69-88,119-138,129-148$, and $149-168$ ) and the $89-96$ amino acid residues form a turn-helix-turn structure that is completely exposed to the surface, which may be a potential site for the insertion of exogenous epitopes (Diethelm-Okita et al., 2000). For individuals who have been previously vaccinated with the DTT vaccine, the Th 588 cell epitopes based on the DTT vaccine will induce a rapid CD4+ memory T cell response (Fraser 
et al., 2014). For example, a TNF- $\alpha$ epitope has been coupled to the insertion site of DTT to develop an anti-TNF- $\alpha$ vaccine, DTNF, demonstrating the potential advantage of a DTT-based epitope vaccine against autoimmune diseases (Zhang et al., 2016).

\section{Tetanus toxoid (TT)}

Since tetanus toxoid (TT) is a carrier protein possessing multiple $\mathrm{CD}^{+}$Th cell epitopes and is associated memory Th subsets, it can be recognized by APCs and presented to CD4 ${ }^{+}$Th cells

(Table 4). As mentioned previously, these Th cells can provide the second signal required for B cell activation (van der Heiden et al., 2017; Da et al., 2017). Recently, it has been reported that a new type of anti-gastrin vaccine using TT as a carrier protein for multiple complex antigens can significantly enhance the immunogenicity of the vaccine (He et al., 2018). Jarząb et al. used tetanus toxoid (TT) as the carrier protein for the several synthetic linear or cyclic OmpC epitope peptides and demonstrated that cyclic peptide conjugated to TT as a potential candidate gainst shigellosis

(Jarzab et al., 2018). Helper epitopes selected from TT fragment C (TTFrC) are typically

associated with the target epitope to stimulate a CD4+ T cell response (e.g., anti-brucellosis and anti-atherosclerosis multi-epitope vaccines) (Saadi et al., 2017; Tourani et al., 2017). TT is also commonly used as a carrier protein for glycoconjugate vaccines (Broker, 2016). For example, the

Vi polysaccharide of typhoid has been combined with TT via chemical bonding to compare the immunogenicity with that of DT and CRM197 as a carrier protein (Arcuri et al., 2017).

\section{Anthrax toxin}

The lethal toxin produced by Bacillus anthracis (B. anthracis) is a bipartite toxin consisting of protective antigen (PA) as the cell binding moiety and lethal factor (LF) as the effector component. 
610 PA has the inherent ability to transport the enzymatically active LF across the host cell membrane

611 into the cytoplasm, leading to the death of the host cell (Liu et al., 2017). PA binds to receptors on

612 host cells, and the resulting PA heptopolymer can bind to three LF molecules. Subsequently, the

613 entire toxin complex is endocytosed by cells. PA undergoes conformational changes due to

614 endocytosis-associated acidification, resulting in transmembrane pores which can facilitate the

615 translocation of LF molecules from the endosome into the cytosol (Shaw \& Starnbach, 2008; Arora

616 et al., 2017). The N-terminal (the first 255 amino acids) of LF (PA binding region) termed LFn,

617 retains PA-binding and translocation capabilities but has no toxic activity. LFn has been used to

618 transfer foreign proteins and peptides into the cytoplasm, where they are processed through the

619 MHC class I antigen presentation pathway, and subsequently induce CTL responses. However, it

has been reported that LFn (as a fusion protein) cannot transfer all proteins into the cytoplasm

621 (Wesche et al., 1998). Shaw et al. fused two epitopes (one CD4+ T-cell epitope and one restricted

epitope by MHC-I) from chicken ovalbumin (Ova) to LFn and demonstrated that this recombinant

protein induced both Ova-specific CD4+ T cell and Ova-specific CD8+ T cell responses in mice

(Shaw \& Starnbach, 2008). Additionally, Chandra et al. demonstrated that the anthrax toxin system

can be used as an ESAT-6 delivery carrier of to induce CTL response against tuberculosis by the

ability of LFn to deliver genetically fused ESAT-6 into the cytosol (Chandra et al., 2006).

OTHER POTENTIAL CO-DELIVERY SYSTEMS OF EPITOPE-BASED

VACCINES

Multiple antigenic peptide (MAP)

630

Although the synthesis of long linear peptides with one or more epitopes can promote their 
631 presentation on MHC I and II molecules and enhance their immunogenicity, these vaccines

632 continue to fail to demonstrate adequate efficacy or improve the overall survival rate (Simanovich 633 et al., 2017). To solve this problem, epitopes can be displayed on a multiple antigenic peptide 634 (MAP) system which contains a core matrix of lysine residues that form a scaffold (Tam, 1988). 635 Currently, the most common strategy is to couple a number of epitope peptides to the dendritic 636 polylysine-scaffold using standard solid phase chemistry (Moyle et al., 2006; Horvath et al., 2004)

637 (Fig. 5A). It has been reported that the MAP-based vaccine, (B4T[thi]), which is composed of four 638 copies of B cell epitopes (amino acid [aa] residues 136 - 154 of the FMDV VP1 protein) which are linked to a $\mathrm{T}$ cell epitope (aa residues 21 - 35 of the FMDV non-structural protein $3 \mathrm{~A}$ ) via thioether bonds can significantly induce an immune response against FMDV (Cubillos et al., 2012). Moreover, Wen et al. designed a novel tetra-branched MAP vaccine, M2e-MAP, which combines four copies of M2e with a foreign Th epitope to provide cross-protection against influenza viruses and may serve as a promising platform for influenza vaccine development (Wen et al., 2016). The immunogenicity of both adjuvanted and non-adjuvanted MAP vaccines composed of three conserved HCV envelope peptides (E1 peptide [aa 315 - 323] and E2 peptide [aa 412 -

419 and aa 516 - 531]) were studied. The results showed that the three HCV envelope MAP peptides exhibit strong immunogenicity and produce higher levels of neutralizing antibodies

648 (Abdelhafez et al., 2017). Tumor vaccines based on MAP may also be an effective way to treat and prevent certain types of cancer (Simanovich et al., 2017).

\section{Self-assembled peptide nanoparticles (SAPNs)}

In the field of epitope vaccine research, natural self-assembled particles that are often used by 
652

researchers are proteins derived from viruses (HBsAg or $\mathrm{HBcAg}$ [mentioned above] and tobacco mosaic virus [TMV] capsid proteins) (Lopez-Sagaseta et al., 2016). With the development of advanced molecular machinery and the construction of sophisticated instruments and materials at an atomic level, a wide-range of materials are being used in SAPN systems (Yang et al., 2012). The SAPN complex is primarily dependent on the selection of suitable building blocks. In the SAPN $\beta$-sheets, both polar and hydrophobic amino acids are arranged in an alternating pattern, and self-assembly can occur spontaneously under suitable conditions (Mandal et al., 2014) (Fig. 6). Indelicato et al. designed a mathematical procedure for the structural classification of a specific class of SAPNs, which provides a toolkit for a systematic exploitation of SAPNs and predicting the density of epitopes on the SAPN surface (Indelicato et al., 2017). In addition, epitopes can be integrated on the surface of peptide nanoparticles by synthesizing in the SAPN system (Friedrich et al., 2016). In addition, monomeric peptides containing self-assembled regions and epitopes can be produced by high throughput expression in vitro (El et al., 2014). Recent studies have shown that the SAPN malaria vaccine, FMP014, based on flagellin can be produced by replacing the D0 and D1 regions of bacterial flagellin with repeated sequences of several antigenic epitope regions (e.g., $\alpha$ TSR and circumsporozoite protein [PfCSP] of Plasmodium falciparum) (Seth et al., 2017). In addition, a vaccine was reported to be constructed by combining two conserved influenza virus antigens, M2e and Helix C, with SAPNs as the carrier and flagellin as the self-assembled adjuvant, and the experimental results from animal models show that the SAPN vaccine demonstrates substantial potential for the prevention and control of influenza viruses (Karch et al., 2017). A novel peptide-based SAPN HPV16 vaccine may also be a promising method of improving the 
673 efficacy of cervical cancer vaccines and can be used as a useful reference for the study of virus-

674 related diseases and specific tumor immunotherapy (Tang et al., 2012).

675 Lipid core peptide (LCP)

676 As a form of vaccine delivery, the lipid core peptide (LCP) system allows for lipid amino acids in

677 water with a poly-lysine core to combine with exogenous epitopes to form nanoparticles displaying

678 a polydispersity (PDI) of 0.3 to 0.5 (Skwarczynski \& Toth, 2011b). It appears that the key to self-

679 assembly into small nanoparticles is to ensure there is a proper balance between the composition

680 of hydrophilic and hydrophobic components (Schulze et al., 2017). In the process of vaccine

development, antigen epitopes are surrounded by phospholipid bimolecular layers, thus avoiding

the degradation of antigenic peptides by enzymes (Azmi et al., 2014) (Fig. 5B). Using the LCP

vector system, the B cell epitope, J14, on the M protein of Streptococcus pyogenes and the epitope

peptides of the SfbI protein can be coupled (Zaman et al., 2012; Zaman et al., 2011; Moyle et al.,

2014). One study demonstrated that an LCP system using BPPCysMPEG as a mucosal adjuvant

was more effective at presenting synthetic epitope peptides (Schulze et al., 2017; Olive et al.,

2007). Noushin et al. combined the antigen site of pre-fusion respiratory syncytial virus (RSV) F

glycoprotein ( $\varnothing$ and II [B cell epitopes]) with PADRE (T helper cell epitope) using the LCP

delivery system and found that the LCP constructs could induce a high level of RSV-specific

antibodies (Jaberolansar et al., 2017). In addition, Nirmal et al. coated the GAS lipopeptide-based

vaccine candidate (LCP-1) on the surface of poly lactide-co-glycolide acid (PLGA) to form

nanoparticles that induced a high antibody response, suggesting that the PLGA-based LCP 
694 several advantageous properties, lipid-based antigen complexes can effectively stimulate both

695 humoral and cellular immune responses. Therefore, lipid-based delivery systems represent 696 potential efficient vaccine adjuvants (Kabiri et al., 2018). For example, several liposome vaccines 697 are currently being investigated in clinical studies (Table 5).

698

699

700

701

702

703

704

705

706

707

708

709

710

711

712

713

714

\section{Polymeric and inorganic nanoparticles}

Some polymers exhibit good stability and biocompatibility, and can encapsulate and carry antigens to target cells (Negahdaripour et al., 2017), such as poly lactide-co-glycolide acid (PLGA), thermoresponsive synthetic polymers (TRP), and N-(2-hydroxypropyl) methacrylamide (HPMA) (Li et al., 2017). Thus, these polymers are often used as organic biological carriers to present multiple epitopes to the immune system (Tam, 1988). Multi-alkyne-functionalized hyperbranched polyglycerol (hbPG) is a globular polymer with multiple branches that displays good biocompatibility and is not immunogenic; its multi-functional dendrimer-like structure provides sufficient space to present multivalent antigens (Glaffig et al., 2014). Based on these characteristics, B cell epitopes of the tumor-associated antigen, MUC1, glycopeptide, and the T cell epitopes of the tetanus toxin, P2, can be coupled in series to each branch of the hbPG; moreover, these nanoscale branched spheres can express the glycopeptide on its surface, resulting in enhanced exposure of the antigens to the immune system (Glaffig et al., 2014; Glaffig et al., 2015). Currently, various vaccines based on polymer nanoparticles are being tested in preclinical and clinical trials, including those for tuberculosis, cancer, and HIV (Table 5).

Nanoparticles (NPs) based on the conjugation of peptide epitopes and polymers display highly promising self-adjuvant properties; however, their lack of biodegradability may lead to serious 
715 deficiencies (Skwarczynski et al., 2010). Chitosan is a non-toxic, muco-adhesive, and

716 biodegradable natural polymer that can be recognized by a variety of receptors (e.g., mannose

717 receptors, TLR2, C-type lectin receptor, Dectin-1, and leukotriene B4 receptors) on the surface of

718 APCs (Li et al., 2013). Chitosan NPs are typically prepared by interacting with anionic

719 crosslinkers, antigens or polymers; anionic tripoly-phosphate (TPP) was typically used as a

720 crosslinking agent in previous studies (Prego et al., 2010). However, Nevagi et al. developed a

721 novel chitosan NPs-based vaccine delivery system produced by the conjugation of a short anionic

722 polymer (PGA) to a peptide antigen possessing a conserved B cell epitope derived from group A

723 streptococcus (GAS) and a universal Th epitope to form NPs with trimethyl chitosan (TMC) via

ionic interactions. The GAS peptide antigen-based chitosan NPs were formulated without the use

of a crosslinking agent and evaluated in mice upon intranasal administration; such studies have

determined that NPs can induce specific mucosal and systemic opsonic antibodies (Nevagi et al.,

2018).

728

Some inorganic materials (e.g., gold, aluminum hydroxide, and carbon nanotubes) also have

excellent biological properties (e.g., good biocompatibility, as well as ease of modification and

processing). Among these, gold nanoparticles have attracted increased attention as antigen carriers

in vaccine research (Negahdaripour et al., 2017) (Fig. 7). Compared with other inorganic

nanoparticles, gold nanoparticles have been widely investigated in clinical studies for epitope-

based vaccine delivery (e.g., influenza, HIV, and Malaria) (Table 5). For example, the Cap protein

of porcine ring type 2 is used to directly react with AuNPs via a unique cysteine sulfhydryl group

to form Cap-AuNPs, which expose neutralized epitopes to the outer surface of gold nanoparticles, 
736 and mice immunized with Cap-AuNP showed that Cap-AuNP could efficiently activate T

737 lymphocytes and balance the immune response of Th1 and Th2 cells (Ding et al., 2017). Recently,

738 researchers have developed a variety of gold nano-vaccines against influenza viruses that are

739 associated with favorable application prospects (Tao et al., 2017; Wang et al., 2017). Wang et al.

740 coupled recombinant trimetric influenza A/Aichi/2/68 (H3N2) HA onto the surface of AuNPs and

741 used flagellin as a built-in adjuvant to develop a FliC-coupled AuNP-HA nano-vaccine (Wang et

742 al., 2018). These studies indicate that there is promising future for polymeric and inorganic

743 nanoparticles in vaccine development.

744 CONCLUSIONS

745 With the expansion of knowledge in the fields of immunology and pathogenic biology, a new era

746 of vaccine science has been established. Such advances have provided a basis for the development

747 of various epitope-based vaccines that have been extensively studied due to their unique

748 advantages, particularly the ability to overcome the safety problems associated with traditional

749 vaccines. To overcome the obstacles associated with epitope-based vaccines (e.g., enzymatic

750 degradation), facilitate recognition by the target cells of the immune system more efficiently, as

751 well as maintain and enhance the efficiency and immunoreactivity of the constructed vaccines, the

752 development of novel built-in adjuvants is a key step in the design of epitope-based vaccines. It is

753 essential to optimize the subunit vaccine antigen design and understand the trends in adjuvant

754 applications, including target antigen processing and its in vivo presentation. To efficiently

755 separate the constructed multi-epitope domains, flexible linkers are often used (e.g., GPGPG and

756 EAAK). The lack of suitable linkers in epitope-based vaccines may lead to the production of novel 
757 structural regions which may interfere with the immunogenicity of exogenous epitopes. In this

758 review, we briefly introduced several commonly used built-in adjuvants (e.g., TLR ligands, VLPs,

759 and several bacterial toxin proteins) with different features and several new potential co-delivery

760 systems for epitope-based antigens. These systems are capable of forming nanoparticles, have no

761 immunogenicity or toxicity, and can display antigen epitopes on the surface of the particles,

762 including MAP, SAPNs, LCP, and polymeric or inorganic nanomaterials. Additionally, carrier

763 proteins with epitopes can serve as chaperones and stimulate the production of immune-related

764 factors, possess CTL and Th-cell epitopes required to generate a humoral and cellular immune

response, or spontaneously assemble into VLPs. The majority of built-in adjuvants (e.g., HSP70,

flagellin, and Chitosan) mentioned in this review are already in clinical trials (Table 5). The

carbohydrate-based conjugate vaccines were prepared using tetanus toxoid (TT), diphtheria toxoid

(DT), meningococcus B outer membrane protein complex (OMPC), and other proteins (e.g.,

keyhole limpet hemocyanin $[\mathrm{KLH}]$ ) used as the carrier molecules (Pichichero, 2013).

Additionally, these protein carriers have achieved great success. For example, a range of

glycoconjugate vaccines against infectious diseases (e.g., H. influenzae type B, Neisseria

meningitidis and pneumonia) have been licensed for clinical use (Astronomo \& Burton, 2010).

There are some approved VLP-based vaccines currently on the market, including recombinant

HBV, hepatitis E virus (HEV), and human papilloma virus (HPV) vaccines. Several VLP vaccines

for different diseases are also being tested in clinical trials (Negahdaripour et al., 2017). However, 
778 as an immunogen may lead to poor responses. Thus, it is particularly important to develop

779 alternative VLPs, such as hepadnaviral or plant virus-derived VLPs (e.g., TMV-based VLPs),

780 some of which could be tested in future clinical trials (Roose et al., 2013). Although some

781 adjuvants are currently used in vaccines licensed for human use, they are usually used as mixtures

782 with antigens. In comparison, antigen-adjuvant fusion can significantly improve immunogenicity

783 and display greater potential to induce an antigen-specific immune response. Based on clinical

784 studies of conjugate vaccines, it is difficult to conclude which built-in adjuvant has a greater

785 influence on vaccine immunogenicity. This is because, in addition to adjuvants and selected

786 epitopes, there are other parameters that affect the immunogenicity of epitope vaccines, including

conjugation chemistry, the presence of a spacer, and degree of conjugation. The development of

future multivalent epitope-based vaccines is primarily dependent on future advances in research

involving built-in adjuvants, which have the characteristics of being easily obtained, good

biological safety, and a high efficiency for displaying epitopes. In the future, we hope to see the

marketing approval of several multiepitope-adjuvant fusion vaccines, as well as increased interest

in the field of built-in adjuvants.

793

794

795

796

797

798

799

800

801

802

\section{REFERENCES:}

Abdelhafez, T.H., Bader, E.D.N., Tabll, A.A., Mashaly, M.M., Dawood, R.M., Yassin, N.A., and El-Awady, M.K. 2017. Mice Antibody Response to Conserved Nonadjuvanted Multiple Antigenic Peptides Derived from E1/E2 Regions of Hepatitis C Virus. VIRAL IMMUNOLOGY 30:359-365. 10.1089/vim.2016.0123

Ajamian, L., Melnychuk, L., Jean-Pierre, P., and Zaharatos, G.J. 2018. DNA Vaccine-Encoded Flagellin Can Be Used as an Adjuvant Scaffold to Augment HIV-1 gp41 Membrane Proximal External Region Immunogenicity. Viruses 10. 10.3390/v10030100

Ali, M., Pandey, R.K., Khatoon, N., Narula, A., Mishra, A., and Prajapati, V.K. 2017. Exploring dengue genome to construct a multi-epitope based subunit vaccine by utilizing immunoinformatics approach to battle against dengue infection. Sci Rep 7:9232. 10.1038/s41598-017-09199-w 
803 Allison, J.P., Benoist, C., and Chervonsky, A.V. 2011. Nobels: Toll pioneers deserve recognition. NATURE 479:178.

$804 \quad 10.1038 / 479178 \mathrm{a}$

805 Arai, Y., Inuki, S., and Fujimoto, Y. 2018. Site-specific effect of polar functional group-modification in lipids of TLR2

806 ligands for modulating the ligand immunostimulatory activity. BIOORGANIC \& MEDICINAL CHEMISTRY

807 LETTERS. 10.1016/j.bmcl.2018.03.042

808 Arcuri, M., Di Benedetto, R., Cunningham, A.F., Saul, A., MacLennan, C.A., and Micoli, F. 2017. The influence of

809 conjugation variables on the design and immunogenicity of a glycoconjugate vaccine against Salmonella Typhi. PLoS

810 One 12:e189100. 10.1371/journal.pone.0189100

811 Arora, G., Misra, R., and Sajid, A. 2017. Model Systems for Pulmonary Infectious Diseases: Paradigms of Anthrax

812 and Tuberculosis. CURRENT TOPICS IN MEDICINAL CHEMISTRY 17:2077-2099.

$81310.2174 / 1568026617666170130111324$

814 Astronomo, R.D., and Burton, D.R. 2010. Carbohydrate vaccines: developing sweet solutions to sticky situations?

815 NATURE REVIEWS DRUG DISCOVERY 9:308-324. 10.1038/nrd3012

816 Azmi, F., Ahmad, F.A., Skwarczynski, M., and Toth, I. 2014. Recent progress in adjuvant discovery for peptide-based

817 subunit vaccines. Hum Vaccin Immunother 10:778-796.

818 Bajzert, J., Gorczykowski, M., Galli, J., and Stefaniak, T. 2018. The evaluation of immunogenic impact of selected 819 bacterial, recombinant Hsp60 antigens in DBA/2J mice. Microb Pathog 115:100-111. 10.1016/j.micpath.2017.12.001

820 Banik, S., Mansour, A.A., Suresh, R.V., Wykoff-Clary, S., Malik, M., McCormick, A.A., and Bakshi, C.S. 2015.

821 Development of a Multivalent Subunit Vaccine against Tularemia Using Tobacco Mosaic Virus (TMV) Based

822 Delivery System. PLoS One 10:e130858. 10.1371/journal.pone.0130858

823 Basto, A.P., and Leitao, A. 2014. Targeting TLR2 for vaccine development. Journal of Immunology Research 824 2014:619410. 10.1155/2014/619410

825 Basu, R., Zhai, L., Contreras, A., and Tumban, E. 2018. Immunization with phage virus-like particles displaying Zika 826 virus potential B-cell epitopes neutralizes Zika virus infection of monkey kidney cells. VACCINE 36:1256-1264.

827 10.1016/j.vaccine.2018.01.056

828 Basu, S., Binder, R.J., Ramalingam, T., and Srivastava, P.K. 2001. CD91 is a common receptor for heat shock proteins gp96, hsp90, hsp70, and calreticulin. IMMUNITY 14:303-313.

830 Batista, M.T., Souza, R.D., Ferreira, E.L., Robinette, R., Crowley, P.J., Rodrigues, J.F., Brady, L.J., Ferreira, L.C., 831 and Ferreira, R.C. 2014. Immunogenicity and in vitro and in vivo protective effects of antibodies targeting a 832 recombinant form of the Streptococcus mutans P1 surface protein. INFECTION AND IMMUNITY 82:4978-4988.

833 10.1128/IAI.02074-14

834 Bellier, B., and Klatzmann, D. 2013. Virus-like particle-based vaccines against hepatitis C virus infection. Expert 835 Review of Vaccines 12:143-154. 10.1586/erv.13.10

836 Bolduc, M., Baz, M., Laliberte-Gagne, M.E., Carignan, D., Garneau, C., Russel, A., Boivin, G., Savard, P., and 837 Leclerc, D. 2018. The quest for a nanoparticle-based vaccine inducing broad protection to influenza viruses. 838 Nanomedicine 14:2563-2574. 10.1016/j.nano.2018.08.010

839 Bolhassani, A., and Rafati, S. 2008. Heat-shock proteins as powerful weapons in vaccine development. Expert Review 840 of Vaccines 7:1185-1199. 10.1586/14760584.7.8.1185

841 Broker, M. 2016. Potential protective immunogenicity of tetanus toxoid, diphtheria toxoid and Cross Reacting 842 Material 197 (CRM197) when used as carrier proteins in glycoconjugates. Hum Vaccin Immunother 12:664-667. $843 \quad 10.1080 / 21645515.2015 .1086048$ 
844 Busseron, E., Ruff, Y., Moulin, E., and Giuseppone, N. 2013. Supramolecular self-assemblies as functional

845 nanomaterials. Nanoscale 5:7098-7140. 10.1039/c3nr02176a

Cai, H., Chen, M.S., Sun, Z.Y., Zhao, Y.F., Kunz, H., and Li, Y.M. 2013. Self-adjuvanting synthetic antitumor vaccines from MUC1 glycopeptides conjugated to T-cell epitopes from tetanus toxoid. Angew Chem Int Ed Engl 52:6106-6110. 10.1002/anie.201300390

Cai, H., Orwenyo, J., Giddens, J.P., Yang, Q., Zhang, R., LaBranche, C.C., Montefiori, D.C., and Wang, L.X. 2017. Synthetic Three-Component HIV-1 V3 Glycopeptide Immunogens Induce Glycan-Dependent Antibody Responses. Cell Chemical Biology 24:1513-1522. 10.1016/j.chembiol.2017.09.005

Carignan, D., Therien, A., Rioux, G., Paquet, G., Gagne, M.L., Bolduc, M., Savard, P., and Leclerc, D. 2015. Engineering of the PapMV vaccine platform with a shortened M2e peptide leads to an effective one dose influenza vaccine. VACCINE 33:7245-7253. 10.1016/j.vaccine.2015.10.123

Caro-Aguilar, I., Ottinger, E., Hepler, R.W., Nahas, D.D., Wu, C., Good, M.F., Batzloff, M., Joyce, J.G., Heinrichs, J.H., and Skinner, J.M. 2013. Immunogenicity in mice and non-human primates of the Group A Streptococcal J8 peptide vaccine candidate conjugated to CRM197. Hum Vaccin Immunother 9:488-496.

Castellino, F., Boucher, P.E., Eichelberg, K., Mayhew, M., Rothman, J.E., Houghton, A.N., and Germain, R.N. 2000. Receptor-mediated uptake of antigen/heat shock protein complexes results in major histocompatibility complex class I antigen presentation via two distinct processing pathways. JOURNAL OF EXPERIMENTAL MEDICINE 191:19571964.

Cervantes-Barragan, L., Gil-Cruz, C., Pastelin-Palacios, R., Lang, K.S., Isibasi, A., Ludewig, B., and Lopez-Macias, C. 2009. TLR2 and TLR4 signaling shapes specific antibody responses to Salmonella typhi antigens. EUROPEAN JOURNAL OF IMMUNOLOGY 39:126-135. 10.1002/eji.200838185

Chandra, S., Kaur, M., Midha, S., Bhatnagar, R., and Banerjee-Bhatnagar, N. 2006. Evaluation of the ability of Nterminal fragment of lethal factor of Bacillus anthracis for delivery of Mycobacterium T cell antigen ESAT-6 into cytosol of antigen presenting cells to elicit effective cytotoxic T lymphocyte response. Biochem Biophys Res Commun 351:702-707. 10.1016/j.bbrc.2006.10.099

Chen, D.J., Osterrieder, N., Metzger, S.M., Buckles, E., Doody, A.M., DeLisa, M.P., and Putnam, D. 2010. Delivery of foreign antigens by engineered outer membrane vesicle vaccines. Proc Natl Acad Sci U S A 107:3099-3104. 10.1073/pnas.0805532107

Chen, Q., Li, W., Wang, P., Shao, H., Ding, Y., Wang, W., Cen, D., Cai, Y., Xue, X., Zhang, L., and Zhu, G. 2017. Induction of Humoral and Cellular Immune Responses in Mice by Multiepitope Vaccines Composing of Both $\mathrm{T}$ and B Lymphocyte Epitopes of MAGE-A3 which are Recombined into HBcAg. Protein Pept Lett 24:947-954. 10.2174/0929866524666170621094921

Cheng, C., Pal, S., Tifrea, D., Jia, Z., and de la Maza, L.M. 2014. A vaccine formulated with a combination of TLR2 and TLR-9 adjuvants and the recombinant major outer membrane protein elicits a robust immune response and significant protection against a Chlamydia muridarum challenge. MICROBES AND INFECTION 16:244-252. 10.1016/j.micinf.2013.11.009

Cheng, L., Yu, L., Wu, X., Li, K., Wang, F., Zhang, L., Ye, W., Li, P., Zhang, F., and Xu, Z. 2014. Induction of specific humoral and cellular immune responses in a mouse model following gene fusion of HSP70C and Hantaan virus Gn and S0.7 in an adenoviral vector. PLoS One 9:e88183. 10.1371/journal.pone.0088183

Chu, X., Li, Y., Long, Q., Xia, Y., Yao, Y., Sun, W., Huang, W., Yang, X., Liu, C., and Ma, Y. 2016. Chimeric HBcAg virus-like particles presenting a HPV 16 E7 epitope significantly suppressed tumor progression through 
885 preventive or therapeutic immunization in a TC-1-grafted mouse model. Int $J$ Nanomedicine 11:2417-2429.

$88610.2147 /$ IJN.S102467

887 Craig, E.A. 2018. Hsp70 at the membrane: driving protein translocation. BMC BIOLOGY 16:11. 10.1186/s12915$888 \quad 017-0474-3$

889 Cubillos, C., de la Torre, B.G., Barcena, J., Andreu, D., Sobrino, F., and Blanco, E. 2012. Inclusion of a specific T 890 cell epitope increases the protection conferred against foot-and-mouth disease virus in pigs by a linear peptide 891 containing an immunodominant B cell site. Virology Journal 9:66. 10.1186/1743-422X-9-66

892 Culver, J.N. 2002. Tobacco mosaic virus assembly and disassembly: determinants in pathogenicity and resistance. 893 Annual Review of Phytopathology 40:287-308. 10.1146/annurev.phyto.40.120301.102400

894 Czarnota, A., Tyborowska, J., Peszynska-Sularz, G., Gromadzka, B., Bienkowska-Szewczyk, K., and Grzyb, K. 2016. 895 Immunogenicity of Leishmania-derived hepatitis B small surface antigen particles exposing highly conserved E2 896 epitope of hepatitis C virus. Microbial Cell Factories 15:62. 10.1186/s12934-016-0460-4

897 Da, H.V., Conceicao, F.R., Dellagostin, O.A., and Doolan, D.L. 2011. Non-toxic derivatives of LT as potent adjuvants. 898 VACCINE 29:1538-1544. 10.1016/j.vaccine.2010.11.091

899 Da, S.A.R., Paul, S., Sidney, J., Weiskopf, D., Dan, J.M., Phillips, E., Mallal, S., Crotty, S., Sette, A., and Lindestam, 900 A.C. 2017. Definition of Human Epitopes Recognized in Tetanus Toxoid and Development of an Assay Strategy to 901 Detect Ex Vivo Tetanus CD4+ T Cell Responses. PLoS One 12:e169086. 10.1371/journal.pone.0169086

902 Dai, S., Zhuo, M., Song, L., Chen, X., Yu, Y., Zang, G., and Tang, Z. 2016. Lentiviral vector encoding ubiquitinated 903 hepatitis B core antigen induces potent cellular immune responses and therapeutic immunity in HBV transgenic 904 mice. IMMUNOBIOLOGY 221:813-821. 10.1016/j.imbio.2016.01.015

905 Daleke-Schermerhorn, M.H., Felix, T., Soprova, Z., Ten, H.C., Vikstrom, D., Majlessi, L., Beskers, J., Follmann, F., 906 de Punder, K., van der Wel, N.N., Baumgarten, T., Pham, T.V., Piersma, S.R., Jimenez, C.R., van Ulsen, P., de Gier, 907 J.W., Leclerc, C., Jong, W.S., and Luirink, J. 2014. Decoration of outer membrane vesicles with multiple antigens by 908 using an autotransporter approach. Appl Environ Microbiol 80:5854-5865. 10.1128/AEM.01941-14

909 Dascher, C.C., Hiromatsu, K., Xiong, X., Morehouse, C., Watts, G., Liu, G., McMurray, D.N., LeClair, K.P., Porcelli, 910 S.A., and Brenner, M.B. 2003. Immunization with a mycobacterial lipid vaccine improves pulmonary pathology in 911 the guinea pig model of tuberculosis. INTERNATIONAL IMMUNOLOGY 15:915-925.

912 Deng, L., Kim, J.R., Chang, T.Z., Zhang, H., Mohan, T., Champion, J.A., and Wang, B. 2017. Protein nanoparticle 913 vaccine based on flagellin carrier fused to influenza conserved epitopes confers full protection against influenza A 914 virus challenge. VIROLOGY 509:82-89. 10.1016/j.virol.2017.06.001

915 Diethelm-Okita, B.M., Okita, D.K., Banaszak, L., and Conti-Fine, B.M. 2000. Universal epitopes for human CD4+ 916 cells on tetanus and diphtheria toxins. JOURNAL OF INFECTIOUS DISEASES 181:1001-1009. 10.1086/315324

917 Ding, L., Meng, Y., Zhang, H.Y., Yin, W.C., Yan, Y., and Cao, Y.P. 2016. Active immunization with the peptide 918 epitope vaccine Abeta3-10-KLH induces a Th2-polarized anti-Abeta antibody response and decreases amyloid 919 plaques in APP/PS1 transgenic mice. NEUROSCIENCE LETTERS 634:1-6. 10.1016/j.neulet.2016.09.050

920 Ding, L., Meng, Y., Zhang, H.Y., Yin, W.C., Yan, Y., and Cao, Y.P. 2017. Prophylactic active immunization with a 921 novel epitope vaccine improves cognitive ability by decreasing amyloid plaques and neuroinflammation in APP/PS1 922 transgenic mice. NEUROSCIENCE RESEARCH 119:7-14. 10.1016/j.neures.2017.01.003

923 Ding, P., Zhang, T., Li, Y., Teng, M., Sun, Y., Liu, X., Chai, S., Zhou, E., Jin, Q., and Zhang, G. 2017. Nanoparticle 924 orientationally displayed antigen epitopes improve neutralizing antibody level in a model of porcine circovirus type 925 2. Int J Nanomedicine 12:5239-5254. 10.2147/IJN.S140789 
926 Ding, Z., Ou, R., Ni, B., Tang, J., and Xu, Y. 2013. Cytolytic activity of the human papillomavirus type 16 E711-20

927 epitope-specific cytotoxic T lymphocyte is enhanced by heat shock protein 110 in HLA-A*0201 transgenic mice.

928 Clinical and Vaccine Immunology 20:1027-1033. 10.1128/CVI.00721-12

929 Dowling, J.K., and Dellacasagrande, J. 2016. Toll-Like Receptors: Ligands, Cell-Based Models, and Readouts for 930 Receptor Action. Methods Mol Biol 1390:3-27. 10.1007/978-1-4939-3335-8_1

931 Dupont, J., Altclas, J., Lepetic, A., Lombardo, M., Vazquez, V., Salgueira, C., Seigelchifer, M., Arndtz, N., Antunez, 932 E., von Eschen, K., and Janowicz, Z. 2006. A controlled clinical trial comparing the safety and immunogenicity of a 933 new adjuvanted hepatitis $\mathrm{B}$ vaccine with a standard hepatitis $\mathrm{B}$ vaccine. VACCINE 24:7167-7174. 934 10.1016/j.vaccine.2006.06.053

935 El, B.K., Zhou, Y., Dasgupta, D., Cobb, D., Dubey, J.P., Burkhard, P., Lanar, D.E., and McLeod, R. 2014. 936 Effectiveness of a novel immunogenic nanoparticle platform for Toxoplasma peptide vaccine in HLA transgenic mice. 937 VACCINE 32:3243-3248. 10.1016/j.vaccine.2014.03.092

938 El, B.K., Zhou, Y., Paulillo, S.M., Raman, S.K., Karch, C.P., Roberts, C.W., Lanar, D.E., Reed, S., Fox, C., Carter, 939 D., Alexander, J., Sette, A., Sidney, J., Lorenzi, H., Begeman, I.J., Burkhard, P., and McLeod, R. 2017. Protein 940 nanovaccine confers robust immunity against Toxoplasma. NPJ Vaccines 2:24. 10.1038/s41541-017-0024-6

941 Eraghi, V., Derakhshandeh, A., Hosseini, A., and Motamedi-Boroojeni, A. 2017. In silico design and expression of a 942 novel fusion protein of HBHA and high antigenic region of FAP-P of Mycobacterium avium subsp. paratuberculosis 943 in Pichia pastoris. Mol Biol Res Commun 6:161-168. 10.22099/mbrc.2017.26522.1286

944 Felzmann, T., Gadner, H., and Holter, W. 2002. Dendritic cells as adjuvants in antitumor immune therapy. Onkologie 945 25:456-464. 10.1159/000067441

946 Foged, C. 2011. Subunit vaccines of the future: the need for safe, customized and optimized particulate delivery 947 systems. Ther Deliv 2:1057-1077.

948 Fraser, C.C., Altreuter, D.H., Ilyinskii, P., Pittet, L., LaMothe, R.A., Keegan, M., Johnston, L., and Kishimoto, T.K. 949 2014. Generation of a universal CD4 memory T cell recall peptide effective in humans, mice and non-human primates. 950 VACCINE 32:2896-2903. 10.1016/j.vaccine.2014.02.024

951 Friedrich, B.M., Beasley, D., and Rudra, J.S. 2016. Supramolecular peptide hydrogel adjuvanted subunit vaccine 952 elicits protective antibody responses against West Nile virus. VACCINE 34:5479-5482. 953 10.1016/j.vaccine.2016.09.044

954 Fu, F., Tian, H., Li, X., Lang, Y., Tong, G., Liu, S., Li, H., Wang, W., Li, X., and Chen, X. 2013. C-terminal heat 955 shock protein 70 of Mycobacterium tuberculosis as a molecular adjuvant for DNA vaccination with the porcine 956 circovirus type 2 ORF2 (capsid) gene in mice. VETERINARY JOURNAL 195:244-247. 10.1016/j.tvj1.2012.06.005

957 Fukui, M., Shinjo, K., Umemura, M., Shigeno, S., Harakuni, T., Arakawa, T., and Matsuzaki, G. 2015. Enhanced 958 effect of BCG vaccine against pulmonary Mycobacterium tuberculosis infection in mice with lung Th17 response to 959 mycobacterial heparin-binding hemagglutinin adhesin antigen. MICROBIOLOGY AND IMMUNOLOGY 59:735-743. $960 \quad 10.1111 / 1348-0421.12340$

961 Gambhira, R., Karanam, B., Jagu, S., Roberts, J.N., Buck, C.B., Bossis, I., Alphs, H., Culp, T., Christensen, N.D., and 962 Roden, R.B. 2007. A protective and broadly cross-neutralizing epitope of human papillomavirus L2. JOURNAL OF 963 VIROLOGY 81:13927-13931. 10.1128/JVI.00936-07

964 Ge, F., Qiu, Y., Gao, X., Yang, Y., and Chen, P. 2006. Fusion expression of major antigenic segment of JEV E protein$965 \mathrm{hsp70}$ and the identification of domain acting as adjuvant in hsp70. VETERINARY IMMUNOLOGY AND 966 IMMUNOPATHOLOGY 113:288-296. 10.1016/j.vetimm.2006.05.012 
967 Gerke, C., Colucci, A.M., Giannelli, C., Sanzone, S., Vitali, C.G., Sollai, L., Rossi, O., Martin, L.B., Auerbach, J., Di 968 Cioccio, V., and Saul, A. 2015. Production of a Shigella sonnei Vaccine Based on Generalized Modules for Membrane 969 Antigens (GMMA), 1790GAHB. PLoS One 10:e134478. 10.1371/journal.pone.0134478

970 Glaffig, M., Palitzsch, B., Hartmann, S., Schüll, C., Nuhn, L., Gerlitzki, B., Schmitt, E., Frey, H., and Kunz, H. 2014.

971 A Fully Synthetic Glycopeptide Antitumor Vaccine Based on Multiple Antigen Presentation on a Hyperbranched 972 Polymer. Chemistry - A European Journal 20:4232-4236. 10.1002/chem.201400256

973 Glaffig, M., Palitzsch, B., Stergiou, N., Schull, C., Strassburger, D., Schmitt, E., Frey, H., and Kunz, H. 2015. 974 Enhanced immunogenicity of multivalent MUC1 glycopeptide antitumour vaccines based on hyperbranched 975 polymers. ORGANIC \& BIOMOLECULAR CHEMISTRY 13:10150-10154. 10.1039/c5ob01255d

976 Gnopo, Y., Watkins, H.C., Stevenson, T.C., DeLisa, M.P., and Putnam, D. 2017. Designer outer membrane vesicles 977 as immunomodulatory systems - Reprogramming bacteria for vaccine delivery. Adv Drug Deliv Rev 114:132-142. 978 10.1016/j.addr.2017.05.003

979 Guo, F., Liu, Y., Zhang, C., Wang, Q., Wang, L., Gao, Y., Bi, J., Wang, H., and Su, Z. 2018. Prompt and Robust 980 Humoral Immunity Elicited by a Conjugated Chimeric Malaria Antigen with a Truncated Flagellin. Bioconjug Chem 981 29:761-770. 10.1021/acs.bioconjchem.7b00320

982 Guo, L., Yang, H., Tang, F., Yin, R., Liu, H., Gong, X., Wei, J., Zhang, Y., Xu, G., and Liu, K. 2017. Oral 983 Immunization with a Multivalent Epitope-Based Vaccine, Based on NAP, Urease, HSP60, and HpaA, Provides 984 Therapeutic Effect on H. pylori Infection in Mongolian gerbils. Front Cell Infect Microbiol 7:349. $98510.3389 /$ fcimb.2017.00349

986 Hajam, I.A., Dar, P.A., Shahnawaz, I., Jaume, J.C., and Lee, J.H. 2017. Bacterial flagellin-a potent immunomodulatory 987 agent. EXPERIMENTAL AND MOLECULAR MEDICINE 49:e373. 10.1038/emm.2017.172

988 Hajighahramani, N., Nezafat, N., Eslami, M., Negahdaripour, M., Rahmatabadi, S.S., and Ghasemi, Y. 2017. 989 Immunoinformatics analysis and in silico designing of a novel multi-epitope peptide vaccine against Staphylococcus 990 aureus. INFECTION GENETICS AND EVOLUTION 48:83-94. 10.1016/j.meegid.2016.12.010

991 Halliday, A., Turner, J.D., Guimaraes, A., Bates, P.A., and Taylor, M.J. 2016. The TLR2/6 ligand PAM2CSK4 is a 992 Th2 polarizing adjuvant in Leishmania major and Brugia malayi murine vaccine models. Parasit Vectors 9:96.

993 10.1186/s13071-016-1381-0

994 He, Q., Gao, H., Gao, M., Qi, S., Yang, K., Zhang, Y., and Wang, J. 2018. Immunogenicity and safety of a novel 995 tetanus toxoid-conjugated anti-gastrin vaccine in BALB/c mice. VACCINE. 10.1016/j.vaccine.2017.12.054

996 Hekmat, S., Sadat, S.M., Aslani, M.M., Mahdavi, M., Bolhassani, A., Asgar, H.F., Ghahari, S., Aghasadeghi, M.R., 997 and Siadat, S.D. 2018. Truncated Core/NS3 Fusion Protein of HCV Adjuvanted with Outer Membrane Vesicles of 998 Neisseria Meningitidis Serogroup B: Potent Inducer of the Murine Immune System. Iran Biomed J.

999 Horvath, A., Olive, C., Karpati, L., Sun, H.K., Good, M., and Toth, I. 2004. Toward the development of a synthetic 1000 group a streptococcal vaccine of high purity and broad protective coverage. JOURNAL OF MEDICINAL CHEMISTRY 1001 47:4100-4104. 10.1021/jm040041w

1002 Hu, J.C., Mathias-Santos, C., Greene, C.J., King-Lyons, N.D., Rodrigues, J.F., Hajishengallis, G., Ferreira, L.C., and 1003 Connell, T.D. 2014. Intradermal administration of the Type II heat-labile enterotoxins LT-IIb and LT-IIc of 1004 enterotoxigenic Escherichia coli enhances humoral and CD8+ T cell immunity to a co-administered antigen. PLoS 1005 One 9:e113978. 10.1371/journal.pone.0113978

1006 Huleatt, J.W., Nakaar, V., Desai, P., Huang, Y., Hewitt, D., Jacobs, A., Tang, J., McDonald, W., Song, L., Evans, 1007 R.K., Umlauf, S., Tussey, L., and Powell, T.J. 2008. Potent immunogenicity and efficacy of a universal influenza 
1008 vaccine candidate comprising a recombinant fusion protein linking influenza M2e to the TLR5 ligand flagellin. 1009 VACCINE 26:201-214. 10.1016/j.vaccine.2007.10.062

1010 Indelicato, G., Burkhard, P., and Twarock, R. 2017. Classification of self-assembling protein nanoparticle 1011 architectures for applications in vaccine design. R Soc Open Sci 4:161092. 10.1098/rsos.161092

1012 Izgi, K., Iskender, B., Sakalar, C., Arslanhan, A., Saraymen, B., and Canatan, H. 2015. Evaluation of two different 1013 adjuvants with immunogenic uroplakin $3 \mathrm{~A}$-derived peptide for their ability to evoke an immune response in mice.

1014 EUROPEAN CYTOKINE NETWORK 26:46-56. 10.1684/ecn.2015.0365

1015 Jaberolansar, N., Chappell, K.J., Watterson, D., Bermingham, I.M., Toth, I., Young, P.R., and Skwarczynski, M. 2017.

1016 Induction of high titred, non-neutralising antibodies by self-adjuvanting peptide epitopes derived from the respiratory 1017 syncytial virus fusion protein. Sci Rep 7:11130. 10.1038/s41598-017-10415-w

1018 Jang, M.H., Kweon, M.N., Iwatani, K., Yamamoto, M., Terahara, K., Sasakawa, C., Suzuki, T., Nochi, T., Yokota, 1019 Y., Rennert, P.D., Hiroi, T., Tamagawa, H., Iijima, H., Kunisawa, J., Yuki, Y., and Kiyono, H. 2004. Intestinal villous 1020 M cells: an antigen entry site in the mucosal epithelium. Proc Natl Acad Sci U S A 101:6110-6115. 1021 10.1073/pnas.0400969101

1022 Jarzab, A., Witkowska, D., Ziomek, E., Setner, B., Czajkowska, A., Dorot, M., Szewczuk, Z., and Gamian, A. 2018. 1023 Cyclic OmpC peptidic epitope conjugated to tetanus toxoid as a potential vaccine candidate against shigellosis. 1024 VACCINE 36:4641-4649. 10.1016/j.vaccine.2018.06.037

1025 Jiang, P., Cai, Y., Chen, J., Ye, X., Mao, S., Zhu, S., Xue, X., Chen, S., and Zhang, L. 2017. Evaluation of tandem 1026 Chlamydia trachomatis MOMP multi-epitopes vaccine in BALB/c mice model. VACCINE 35:3096-3103. 1027 10.1016/j.vaccine.2017.04.031

1028 Jiang, S., Li, X., Hess, N.J., Guan, Y., and Tapping, R.I. 2016. TLR10 Is a Negative Regulator of Both MyD881029 Dependent and -Independent TLR Signaling. JOURNAL OF IMMUNOLOGY 196:3834-3841. 1030 10.4049/jimmunol.1502599

1031 Jin, M.S., Kim, S.E., Heo, J.Y., Lee, M.E., Kim, H.M., Paik, S.G., Lee, H., and Lee, J.O. 2007. Crystal structure of 1032 the TLR1-TLR2 heterodimer induced by binding of a tri-acylated lipopeptide. CELL 130:1071-1082. 1033 10.1016/j.cell.2007.09.008

1034 Jong, W.S., Daleke-Schermerhorn, M.H., Vikstrom, D., Ten, H.C., de Punder, K., van der Wel, N.N., van de Sandt, 1035 C.E., Rimmelzwaan, G.F., Follmann, F., Agger, E.M., Andersen, P., de Gier, J.W., and Luirink, J. 2014. An 1036 autotransporter display platform for the development of multivalent recombinant bacterial vector vaccines. Microbial 1037 Cell Factories 13:162. 10.1186/s12934-014-0162-8

1038 Jung, I.D., Jeong, S.K., Lee, C.M., Noh, K.T., Heo, D.R., Shin, Y.K., Yun, C.H., Koh, W.J., Akira, S., Whang, J., 1039 Kim, H.J., Park, W.S., Shin, S.J., and Park, Y.M. 2011. Enhanced efficacy of therapeutic cancer vaccines produced 1040 by co-treatment with Mycobacterium tuberculosis heparin-binding hemagglutinin, a novel TLR4 agonist. CANCER 1041 RESEARCH 71:2858-2870. 10.1158/0008-5472.CAN-10-3487

1042 Juwono, J., and Martinus, R.D. 2016. Does Hsp60 Provide a Link between Mitochondrial Stress and Inflammation in 1043 Diabetes Mellitus? Journal of Diabetes Research 2016:8017571. 10.1155/2016/8017571

1044 Kabiri, M., Sankian, M., Hosseinpour, M., and Tafaghodi, M. 2018. The novel immunogenic chimeric peptide vaccine 1045 to elicit potent cellular and mucosal immune responses against HTLV-1. Int J Pharm 549:404-414. 1046 10.1016/j.ijpharm.2018.07.069

1047 Kalnin, K., Chivukula, S., Tibbitts, T., Yan, Y., Stegalkina, S., Shen, L., Cieszynski, J., Costa, V., Sabharwal, R., 1048 Anderson, S.F., Christensen, N., Jagu, S., Roden, R.B.S., and Kleanthous, H. 2017. Incorporation of RG1 epitope 
1049

1050

1051

1052

1053

1054

1055

1056

1057

1058

1059

1060

1061

1062

1063

1064

1065

1066

1067

1068

1069

1070

1071

1072

1073

1074

1075

1076

1077

1078

1079

1080

1081

1082

1083

1084

1085

1086

1087

1088

1089

concatemers into a self-adjuvanting Flagellin-L2 vaccine broaden durable protection against cutaneous challenge with diverse human papillomavirus genotypes. VACCINE 35:4942-4951. 10.1016/j.vaccine.2017.07.086

Kalnin, K., Tibbitts, T., Yan, Y., Stegalkina, S., Shen, L., Costa, V., Sabharwal, R., Anderson, S.F., Day, P.M., Christensen, N., Schiller, J.T., Jagu, S., Roden, R.B., Almond, J., and Kleanthous, H. 2014. Low doses of flagellinL2 multimer vaccines protect against challenge with diverse papillomavirus genotypes. VACCINE 32:3540-3547. 10.1016/j.vaccine.2014.04.032

Kamboj, K.K., King, C.L., Greenspan, N.S., Kirchner, H.L., and Schreiber, J.R. 2001. Immunization with Haemophilus influenzae type b-CRM(197) conjugate vaccine elicits a mixed Th1 and Th2 CD(4+) T cell cytokine response that correlates with the isotype of antipolysaccharide antibody. JOURNAL OF INFECTIOUS DISEASES 184:931-935. 10.1086/323342

Karch, C.P., Li, J., Kulangara, C., Paulillo, S.M., Raman, S.K., Emadi, S., Tan, A., Helal, Z.H., Fan, Q., Khan, M.I., and Burkhard, P. 2017. Vaccination with self-adjuvanted protein nanoparticles provides protection against lethal influenza challenge. Nanomedicine 13:241-251. 10.1016/j.nano.2016.08.030

Karch, C.P., and Burkhard, P. 2016. Vaccine technologies: From whole organisms to rationally designed protein assemblies. BIOCHEMICAL PHARMACOLOGY 120:1-14. 10.1016/j.bcp.2016.05.001

Karuturi, B., Tallapaka, S.B., Yeapuri, P., Curran, S.M., Sanderson, S.D., and Vetro, J.A. 2017. Encapsulation of an EP67-Conjugated CTL Peptide Vaccine in Nanoscale Biodegradable Particles Increases the Efficacy of Respiratory Immunization and Affects the Magnitude and Memory Subsets of Vaccine-Generated Mucosal and Systemic CD8(+) T Cells in a Diameter-Dependent Manner. Mol Pharm 14:1469-1481. 10.1021/acs.molpharmaceut.6b01088

Kawakami, R., Nozato, Y., Nakagami, H., Ikeda, Y., Shimamura, M., Yoshida, S., Sun, J., Kawano, T., Takami, Y., Noma, T., Rakugi, H., Minamino, T., and Morishita, R. 2018. Development of vaccine for dyslipidemia targeted to a proprotein convertase subtilisin/kexin type 9 (PCSK9) epitope in mice. PLoS One 13:e191895. 10.1371/journal.pone.0191895

Kemnade, J.O., Seethammagari, M., Collinson-Pautz, M., Kaur, H., Spencer, D.M., and McCormick, A.A. 2014. Tobacco mosaic virus efficiently targets DC uptake, activation and antigen-specific $\mathrm{T}$ cell responses in vivo. VACCINE 32:4228-4233. 10.1016/j.vaccine.2014.04.051

Khader, S.A., Bell, G.K., Pearl, J.E., Fountain, J.J., Rangel-Moreno, J., Cilley, G.E., Shen, F., Eaton, S.M., Gaffen, S.L., Swain, S.L., Locksley, R.M., Haynes, L., Randall, T.D., and Cooper, A.M. 2007. IL-23 and IL-17 in the establishment of protective pulmonary $\mathrm{CD} 4+\mathrm{T}$ cell responses after vaccination and during Mycobacterium tuberculosis challenge. NATURE IMMUNOLOGY 8:369-377. 10.1038/ni1449

Kim, J., Yang, Y.L., Jang, S.H., and Jang, Y.S. 2018. Human beta-defensin 2 plays a regulatory role in innate antiviral immunity and is capable of potentiating the induction of antigen-specific immunity. Virology Journal 15:124. 10.1186/s12985-018-1035-2

Kim, J.Y., Doody, A.M., Chen, D.J., Cremona, G.H., Shuler, M.L., Putnam, D., and DeLisa, M.P. 2008. Engineered bacterial outer membrane vesicles with enhanced functionality. JOURNAL OF MOLECULAR BIOLOGY 380:51-66. 10.1016/j.jmb.2008.03.076

Kitaoka, M., Naritomi, A., Kawabe, Y., Kamihira, M., Kamiya, N., and Goto, M. 2017. Transcutaneous pollinosis immunotherapy using a solid-in-oil nanodispersion system carrying T cell epitope peptide and R848. Bioeng Transl Med 2:102-108. 10.1002/btm2.10048

Kuipers, K., Daleke-Schermerhorn, M.H., Jong, W.S., Ten, H.C., van Opzeeland, F., Simonetti, E., Luirink, J., and de Jonge, M.I. 2015. Salmonella outer membrane vesicles displaying high densities of pneumococcal antigen at the 
1090 surface offer protection against colonization. VACCINE 33:2022-2029. 10.1016/j.vaccine.2015.03.010

1091 Kurkjian, C.J., Guo, H., Montgomery, N.D., Cheng, N., Yuan, H., Merrill, J.R., Sempowski, G.D., Brickey, W.J., and

1092 Ting, J.P. 2017. The Toll-Like Receptor 2/6 Agonist, FSL-1 Lipopeptide, Therapeutically Mitigates Acute Radiation 1093 Syndrome. Sci Rep 7:17355. 10.1038/s41598-017-17729-9

1094 Lacasse, P., Denis, J., Lapointe, R., Leclerc, D., and Lamarre, A. 2008. Novel plant virus-based vaccine induces 1095 protective cytotoxic T-lymphocyte-mediated antiviral immunity through dendritic cell maturation. JOURNAL OF 1096 VIROLOGY 82:785-794. 10.1128/JVI.01811-07

1097 Ladokhin, A.S. 2013. pH-triggered conformational switching along the membrane insertion pathway of the diphtheria 1098 toxin T-domain. Toxins (Basel) 5:1362-1380. 10.3390/toxins5081362

1099 Lagoutte, P., Mignon, C., Donnat, S., Stadthagen, G., Mast, J., Sodoyer, R., Lugari, A., and Werle, B. 2016. Scalable 1100 chromatography-based purification of virus-like particle carrier for epitope based influenza A vaccine produced in 1101 Escherichia coli. JOURNAL OF VIROLOGICAL METHODS 232:8-11. 10.1016/j.jviromet.2016.02.011

1102 Leclerc, D., Rivest, M., Babin, C., Lopez-Macias, C., and Savard, P. 2013. A novel M2e based flu vaccine formulation 1103 for dogs. PLoS One 8:e77084. 10.1371/journal.pone.0077084

1104 Lee, B.O., Tucker, A., Frelin, L., Sallberg, M., Jones, J., Peters, C., Hughes, J., Whitacre, D., Darsow, B., Peterson, 1105 D.L., and Milich, D.R. 2009. Interaction of the hepatitis B core antigen and the innate immune system. JOURNAL OF 1106 IMMUNOLOGY 182:6670-6681. 10.4049/jimmunol.0803683

1107 Lencer, W.I., Hirst, T.R., and Holmes, R.K. 1999. Membrane traffic and the cellular uptake of cholera toxin. Biochim 1108 Biophys Acta 1450:177-190.

1109 Li, L., Zhou, M., and Huang, Y. 2017. Synergistic enhancement of anticancer therapeutic efficacy of HPMA 1110 copolymer doxorubicin conjugates via combination of ligand modification and stimuli-response srategies. Int J Pharm $1111536: 450-458$. 10.1016/j.ijpharm.2017.12.018

1112 Li, Q., and Guo, Z. 2018. Recent Advances in Toll Like Receptor-Targeting Glycoconjugate Vaccines. MOLECULES 1113 23. 10.3390/molecules23071583

1114 Li, X., Min, M., Du N, Gu, Y., Hode, T., Naylor, M., Chen, D., Nordquist, R.E., and Chen, W.R. 2013. Chitin, chitosan, 1115 and glycated chitosan regulate immune responses: the novel adjuvants for cancer vaccine. Clin Dev Immunol 1116 2013:387023. 10.1155/2013/387023

1117 Li, X., Yang, X., Li, L., Liu, H., and Liu, J. 2006. A truncated C-terminal fragment of Mycobacterium tuberculosis 1118 HSP70 gene enhanced potency of HBV DNA vaccine. VACCINE 24:3321-3331. 10.1016/j.vaccine.2006.01.012

1119 Liang, P., Yi, Y., Su, Q.D., Qiu, F., Fan, X.T., Lu, X.X., and Bi, S.L. 2018. Efficient Humoral and Cellular Immune 1120 Responses Induced by a Chimeric Virus-like Particle Displaying the Epitope of EV71 without Adjuvant. 1121 BIOMEDICAL AND ENVIRONMENTAL SCIENCES 31:343-350. 10.3967/bes2018.045

1122 Liu, Q., Tan, K., Yuan, J., Song, K., Li, R., Huang, X., and Liu, Q. 2018. Flagellin-deficient outer membrane vesicles 1123 as adjuvant induce cross-protection of Salmonella Typhimurium outer membrane proteins against infection by 1124 heterologous Salmonella serotypes. INTERNATIONAL JOURNAL OF MEDICAL MICROBIOLOGY 308:796-802. 1125 10.1016/j.ijmm.2018.06.001

1126 Liu, R., Vaishnav, R.A., Roberts, A.M., and Friedland, R.P. 2013. Humans have antibodies against a plant virus: 1127 evidence from tobacco mosaic virus. PLoS One 8:e60621. 10.1371/journal.pone.0060621

1128 Liu, S., Ma, Q., Fattah, R., Bugge, T.H., and Leppla, S.H. 2017. Anti-tumor activity of anthrax toxin variants that 1129 form a functional translocation pore by intermolecular complementation. Oncotarget 8:65123-65131. $1130 \quad 10.18632$ /oncotarget. 17729 
1131 Liu, Y., Zhang, W., He, Q., Yu, F., Song, T., Liu, T., Zhang, Z., Zhou, J., Wang, P.G., and Zhao, W. 2016. Fully 1132 synthetic self-adjuvanting MUC1-fibroblast stimulating lipopeptide 1 conjugates as potential cancer vaccines. Chem 1133 Commun (Camb) 52:10886-10889. 10.1039/c6cc04623a

1134 Long, Q., Huang, W., Yao, Y., Yang, X., Sun, W., Jin, X., Li, Y., Chu, X., Liu, C., Peng, Z., and Ma, Y. 2014. Virus1135 like particles presenting interleukin-33 molecules: immunization characteristics and potentials of blockingIL-33/ST2 1136 pathway in allergic airway inflammation. Hum Vaccin Immunother 10:2303-2311. 10.4161/hv.29425

1137 Lopez-Sagaseta, J., Malito, E., Rappuoli, R., and Bottomley, M.J. 2016. Self-assembling protein nanoparticles in the 1138 design of vaccines. Comput Struct Biotechnol J 14:58-68. 10.1016/j.csbj.2015.11.001

1139 Luiz, W.B., Rodrigues, J.F., Crabb, J.H., Savarino, S.J., and Ferreira, L.C. 2015. Maternal vaccination with a fimbrial 1140 tip adhesin and passive protection of neonatal mice against lethal human enterotoxigenic Escherichia coli challenge. 1141 INFECTION AND IMMUNITY 83:4555-4564. 10.1128/IAI.00858-15

1142 MacLennan, C.A., Martin, L.B., and Micoli, F. 2014. Vaccines against invasive Salmonella disease: current status and 1143 future directions. Hum Vaccin Immunother 10:1478-1493. 10.4161/hv.29054

1144 Malito, E., Bursulaya, B., Chen, C., Lo, S.P., Picchianti, M., Balducci, E., Biancucci, M., Brock, A., Berti, F., 1145 Bottomley, M.J., Nissum, M., Costantino, P., Rappuoli, R., and Spraggon, G. 2012. Structural basis for lack of toxicity 1146 of the diphtheria toxin mutant CRM197. Proc Natl Acad Sci U S A 109:5229-5234. 10.1073/pnas.1201964109

1147 Mandal, D., Nasrolahi, S.A., and Parang, K. 2014. Self-assembly of peptides to nanostructures. ORGANIC \& 1148 BIOMOLECULAR CHEMISTRY 12:3544-3561. 10.1039/c4ob00447g

1149 Marasini, N., Khalil, Z.G., Giddam, A.K., Ghaffar, K.A., Hussein, W.M., Capon, R.J., Batzloff, M.R., Good, M.F., 1150 Skwarczynski, M., and Toth, I. 2016. Lipid core peptide/poly(lactic-co-glycolic acid) as a highly potent intranasal 1151 vaccine delivery system against Group A streptococcus. Int J Pharm 513:410-420. 10.1016/j.ijpharm.2016.09.057

1152 McCormick, A.A., Corbo, T.A., Wykoff-Clary, S., Nguyen, L.V., Smith, M.L., Palmer, K.E., and Pogue, G.P. 2006.

1153 TMV-peptide fusion vaccines induce cell-mediated immune responses and tumor protection in two murine models.

1154 VACCINE 24:6414-6423. 10.1016/j.vaccine.2006.06.003

1155 McDonald, D.M., Byrne, S.N., and Payne, R.J. 2015. Synthetic self-adjuvanting glycopeptide cancer vaccines. 1156 Frontiers in Chemistry 3:60. 10.3389/fchem.2015.00060

1157 McDonald, D.M., Wilkinson, B.L., Corcilius, L., Thaysen-Andersen, M., Byrne, S.N., and Payne, R.J. 2014. Synthesis 1158 and immunological evaluation of self-adjuvanting MUC1-macrophage activating lipopeptide 2 conjugate vaccine 1159 candidates. Chem Commun (Camb) 50:10273-10276. 10.1039/c4cc03510k

1160 Micoli, F., Rondini, S., Alfini, R., Lanzilao, L., Necchi, F., Negrea, A., Rossi, O., Brandt, C., Clare, S., Mastroeni, P., 1161 Rappuoli, R., Saul, A., and MacLennan, C.A. 2018. Comparative immunogenicity and efficacy of equivalent outer 1162 membrane vesicle and glycoconjugate vaccines against nontyphoidal Salmonella. Proc Natl Acad Sci U S A 1163 115:10428-10433. 10.1073/pnas.1807655115

1164 Milich, D.R., McLachlan, A., Thornton, G.B., and Hughes, J.L. 1987. Antibody production to the nucleocapsid and 1165 envelope of the hepatitis B virus primed by a single synthetic T cell site. NATURE 329:547-549. 10.1038/329547a0 1166 Moody, D.B., Ulrichs, T., Muhlecker, W., Young, D.C., Gurcha, S.S., Grant, E., Rosat, J.P., Brenner, M.B., Costello, 1167 C.E., Besra, G.S., and Porcelli, S.A. 2000. CD1c-mediated T-cell recognition of isoprenoid glycolipids in 1168 Mycobacterium tuberculosis infection. NATURE 404:884-888. 10.1038/35009119

1169 Mora, D., Salman, M.D., Myrick, C.A., Rhyan, J.C., Miller, L.A., Saetre, E.M., and Eckery, D.C. 2017. Evaluation of 1170 antibody response to an adjuvanted hapten-protein vaccine as a potential inhibitor of sexual maturation for farmed 1171 Atlantic salmon. Fish Shellfish Immunol 71:255-263. 10.1016/j.fsi.2017.08.038 
1172 Moreno-Eutimio, M.A., Tenorio-Calvo, A., Pastelin-Palacios, R., Perez-Shibayama, C., Gil-Cruz, C., Lopez-Santiago,

1173 R., Baeza, I., Fernandez-Mora, M., Bonifaz, L., Isibasi, A., Calva, E., and Lopez-Macias, C. 2013. Salmonella Typhi

1174 OmpS1 and OmpS2 porins are potent protective immunogens with adjuvant properties. IMMUNOLOGY 139:459-

1175 471. 10.1111/imm.12093

1176 Moyle, P.M. 2017. Biotechnology approaches to produce potent, self-adjuvanting antigen-adjuvant fusion protein

1177

1178

1179

1180

1181

1182

1183

1184

1185

1186

1187

1188

1189

1190

1191

1192

1193

1194

1195

1196

1197

1198

1199

1200

1201

1202

1203

1204

1205

1206

1207

1208

1209

1210

1211

1212

\begin{abstract}
subunit vaccines. BIOTECHNOLOGY ADVANCES 35:375-389. 10.1016/j.biotechadv.2017.03.005
\end{abstract}
Moyle, P.M., Dai, W., Zhang, Y., Batzloff, M.R., Good, M.F., and Toth, I. 2014. Site-specific incorporation of three toll-like receptor 2 targeting adjuvants into semisynthetic, molecularly defined nanoparticles: application to group a streptococcal vaccines. Bioconjug Chem 25:965-978. 10.1021/bc500108b

Moyle, P.M., Olive, C., Ho, M.F., Good, M.F., and Toth, I. 2006. Synthesis of a highly pure lipid core peptide based self-adjuvanting triepitopic group A streptococcal vaccine, and subsequent immunological evaluation. JOURNAL OF MEDICINAL CHEMISTRY 49:6364-6370. 10.1021/jm060475m

Moyle, P.M., and Toth, I. 2013. Modern subunit vaccines: development, components, and research opportunities. ChemMedChem 8:360-376. 10.1002/cmdc.201200487

Muhlradt, P.F., Kiess, M., Meyer, H., Sussmuth, R., and Jung, G. 1997. Isolation, structure elucidation, and synthesis of a macrophage stimulatory lipopeptide from Mycoplasma fermentans acting at picomolar concentration. JOURNAL OF EXPERIMENTAL MEDICINE 185:1951-1958.

Murthy, K.G., Deb, A., Goonesekera, S., Szabo, C., and Salzman, A.L. 2004. Identification of conserved domains in Salmonella muenchen flagellin that are essential for its ability to activate TLR5 and to induce an inflammatory response in vitro. JOURNAL OF BIOLOGICAL CHEMISTRY 279:5667-5675. 10.1074/jbc.M307759200

Nalla, N., Pallavi, P., Reddy, B.S., Miryala, S., Naveen, K.V., Mahboob, M., and Halmuthur, M.S. 2015. Design, synthesis and immunological evaluation of 1,2,3-triazole-tethered carbohydrate-Pam3Cys conjugates as TLR2 agonists. Bioorg Med Chem 23:5846-5855. 10.1016/j.bmc.2015.06.070

Narula, A., Pandey, R.K., Khatoon, N., Mishra, A., and Prajapati, V.K. 2018. Excavating chikungunya genome to design $\mathrm{B}$ and $\mathrm{T}$ cell multi-epitope subunit vaccine using comprehensive immunoinformatics approach to control chikungunya infection. INFECTION GENETICS AND EVOLUTION 61:4-15. 10.1016/j.meegid.2018.03.007

Negahdaripour, M., Eslami, M., Nezafat, N., Hajighahramani, N., Ghoshoon, M.B., Shoolian, E., Dehshahri, A., Erfani, N., Morowvat, M.H., and Ghasemi, Y. 2017a. A novel HPV prophylactic peptide vaccine, designed by immunoinformatics and structural vaccinology approaches. INFECTION GENETICS AND EVOLUTION 54:402-416. 10.1016/j.meegid.2017.08.002

Negahdaripour, M., Golkar, N., Hajighahramani, N., Kianpour, S., Nezafat, N., and Ghasemi, Y. 2017b. Harnessing self-assembled peptide nanoparticles in epitope vaccine design. BIOTECHNOLOGY ADVANCES 35:575-596. 10.1016/j.biotechadv.2017.05.002

Negahdaripour, M., Nezafat, N., Eslami, M., Ghoshoon, M.B., Shoolian, E., Najafipour, S., Morowvat, M.H., Dehshahri, A., Erfani, N., and Ghasemi, Y. 2017c. Structural vaccinology considerations for in silico designing of a multi-epitope vaccine. INFECTION GENETICS AND EVOLUTION 58:96-109. 10.1016/j.meegid.2017.12.008

Nempont, C., Cayet, D., Rumbo, M., Bompard, C., Villeret, V., and Sirard, J.C. 2008. Deletion of flagellin's hypervariable region abrogates antibody-mediated neutralization and systemic activation of TLR5-dependent immunity. JOURNAL OF IMMUNOLOGY 181:2036-2043.

Nevagi, R.J., Khalil, Z.G., Hussein, W.M., Powell, J., Batzloff, M.R., Capon, R.J., Good, M.F., Skwarczynski, M., and Toth, I. 2018. Polyglutamic acid-trimethyl chitosan-based intranasal peptide nano-vaccine induces potent immune

PeerJ reviewing PDF | (2018:08:30412:2:0:NEW 23 Nov 2018) 
1213 responses against group A streptococcus. Acta Biomaterialia. 10.1016/j.actbio.2018.09.037

1214 Nezafat, N., Eslami, M., Negahdaripour, M., Rahbar, M.R., and Ghasemi, Y. 2017. Designing an efficient multi1215 epitope oral vaccine against Helicobacter pylori using immunoinformatics and structural vaccinology approaches.

1216 Molecular BioSystems 13:699-713. 10.1039/c6mb00772d

1217 Nezafat, N., Ghasemi, Y., Javadi, G., Khoshnoud, M.J., and Omidinia, E. 2014. A novel multi-epitope peptide vaccine 1218 against cancer: an in silico approach. JOURNAL OF THEORETICAL BIOLOGY 349:121-134. $121910.1016 /$ j.jtbi.2014.01.018

1220 Nezafat, N., Karimi, Z., Eslami, M., Mohkam, M., Zandian, S., and Ghasemi, Y. 2016. Designing an efficient multiepitope peptide vaccine against Vibrio cholerae via combined immunoinformatics and protein interaction based approaches. COMPUTATIONAL BIOLOGY AND CHEMISTRY 62:82-95. 10.1016/j.compbiolchem.2016.04.006 Nezafat, N., Sadraeian, M., Rahbar, M.R., Khoshnoud, M.J., Mohkam, M., Gholami, A., Banihashemi, M., and Ghasemi, Y. 2015. Production of a novel multi-epitope peptide vaccine for cancer immunotherapy in TC-1 tumorbearing mice. BIOLOGICALS 43:11-17. 10.1016/j.biologicals.2014.11.001

Olive, C., Schulze, K., Sun, H.K., Ebensen, T., Horvath, A., Toth, I., and Guzman, C.A. 2007. Enhanced protection against Streptococcus pyogenes infection by intranasal vaccination with a dual antigen component $\mathrm{M}$ protein/SfbI lipid core peptide vaccine formulation. VACCINE 25:1789-1797. 10.1016/j.vaccine.2006.11.031 Ong, H.K., Tan, W.S., and Ho, K.L. 2017. Virus like particles as a platform for cancer vaccine development. PeerJ 5:e4053. 10.7717/peerj.4053

Pandey, H., Fatma, F., Yabaji, S.M., Kumari, M., Tripathi, S., Srivastava, K., Tripathi, D.K., Kant, S., Srivastava, K.K., and Arora, A. 2018. Biophysical and immunological characterization of the ESX-4 system ESAT-6 family proteins Rv3444c and Rv3445c from Mycobacterium tuberculosis H37Rv. Tuberculosis (Edinb) 109:85-96. 10.1016/j.tube.2018.02.002

Pearl, L.H., Prodromou, C., and Workman, P. 2008. The Hsp90 molecular chaperone: an open and shut case for treatment. BIOCHEMICAL JOURNAL 410:439-453. 10.1042/BJ20071640

Perez-Toledo, M., Valero-Pacheco, N., Pastelin-Palacios, R., Gil-Cruz, C., Perez-Shibayama, C., Moreno-Eutimio, M.A., Becker, I., Perez-Tapia, S.M., Arriaga-Pizano, L., Cunningham, A.F., Isibasi, A., Bonifaz, L.C., and LopezMacias, C. 2017. Salmonella Typhi Porins OmpC and OmpF Are Potent Adjuvants for T-Dependent and TIndependent Antigens. Frontiers in Immunology 8:230. 10.3389/fimmu.2017.00230 Persing, D.H., Coler, R.N., Lacy, M.J., Johnson, D.A., Baldridge, J.R., Hershberg, R.M., and Reed, S.G. 2002. Taking toll: lipid A mimetics as adjuvants and immunomodulators. TRENDS IN MICROBIOLOGY 10:S32-S37. Pichichero, M.E. 2013. Protein carriers of conjugate vaccines: characteristics, development, and clinical trials. Hum Vaccin Immunother 9:2505-2523. 10.4161/hv.26109 Pinkhasov, J., Alvarez, M.L., Pathangey, L.B., Tinder, T.L., Mason, H.S., Walmsley, A.M., Gendler, S.J., and Mukherjee, P. 2010. Analysis of a cholera toxin B subunit (CTB) and human mucin 1 (MUC1) conjugate protein in a MUC1-tolerant mouse model. Cancer Immunol Immunother 59:1801-1811. 10.1007/s00262-010-0906-1 Plummer, E.M., and Manchester, M. 2011. Viral nanoparticles and virus-like particles: platforms for contemporary vaccine design. Wiley Interdiscip Rev Nanomed Nanobiotechnol 3:174-196. 10.1002/wnan.119 Prasanphanich, N.S., Song, X., Heimburg-Molinaro, J., Luyai, A.E., Lasanajak, Y., Cutler, C.E., Smith, D.F., and Cummings, R.D. 2015. Intact reducing glycan promotes the specific immune response to lacto-N-neotetraose-BSA neoglycoconjugates. Bioconjug Chem 26:559-571. 10.1021/acs.bioconjchem.5b00036 
1254 based nanoparticles for improving immunization against hepatitis $\mathrm{B}$ infection. VACCINE 28:2607-2614.

1255 10.1016/j.vaccine.2010.01.011

1256 Pumpens, P., Renhofa, R., Dishlers, A., Kozlovska, T., Ose, V., Pushko, P., Tars, K., Grens, E., and Bachmann, M.F.

1257 2016. The True Story and Advantages of RNA Phage Capsids as Nanotools. INTERVIROLOGY 59:74-110.

$1258 \quad 10.1159 / 000449503$

1259 Ramasamy, V., Arora, U., Shukla, R., Poddar, A., Shanmugam, R.K., White, L.J., Mattocks, M.M., Raut, R., Perween, 1260 A., Tyagi, P., de Silva, A.M., Bhaumik, S.K., Kaja, M.K., Villinger, F., Ahmed, R., Johnston, R.E., Swaminathan, S., 1261 and Khanna, N. 2018. A tetravalent virus-like particle vaccine designed to display domain III of dengue envelope 1262 proteins induces multi-serotype neutralizing antibodies in mice and macaques which confer protection against 1263 antibody dependent enhancement in AG129 mice. PLoS Negl Trop Dis 12:e6191. 10.1371/journal.pntd.0006191

1264 Ramirez, A., Morris, S., Maucourant, S., D'Ascanio, I., Crescente, V., Lu, I.N., Farinelle, S., Muller, C.P., Whelan, 1265 M., and Rosenberg, W. 2018. A virus-like particle vaccine candidate for influenza A virus based on multiple conserved 1266 antigens presented on hepatitis B tandem core particles. VACCINE 36:873-880. 10.1016/j.vaccine.2017.12.053

1267 Rana, A., Rub, A., and Akhter, Y. 2014. Proteome-scale identification of outer membrane proteins in Mycobacterium 1268 avium subspecies paratuberculosis using a structure based combined hierarchical approach. Molecular BioSystems 1269 10:2329-2337. 10.1039/c4mb00234b

1270 Rana, A., and Akhter, Y. 2016. A multi-subunit based, thermodynamically stable model vaccine using combined 1271 immunoinformatics and protein structure based approach. IMMUNOBIOLOGY 221:544-557. 1272 10.1016/j.imbio.2015.12.004

1273 Rappazzo, C.G., Watkins, H.C., Guarino, C.M., Chau, A., Lopez, J.L., DeLisa, M.P., Leifer, C.A., Whittaker, G.R., 1274 and Putnam, D. 2016. Recombinant M2e outer membrane vesicle vaccines protect against lethal influenza A 1275 challenge in BALB/c mice. VACCINE 34:1252-1258. 10.1016/j.vaccine.2016.01.028

1276 Reynolds, T.D., Buonocore, L., Rose, N.F., Rose, J.K., and Robek, M.D. 2015. Virus-Like Vesicle-Based Therapeutic

1277 Vaccine Vectors for Chronic Hepatitis B Virus Infection. JOURNAL OF VIROLOGY 89:10407-10415. 1278 10.1128/JVI.01184-15

1279 Rios-Huerta, R., Monreal-Escalante, E., Govea-Alonso, D.O., Angulo, C., and Rosales-Mendoza, S. 2017. Expression 1280 of an immunogenic LTB-based chimeric protein targeting Zaire ebolavirus epitopes from GP1 in plant cells. PLANT 1281 CELL REPORTS 36:355-365. 10.1007/s00299-016-2088-6

1282 Robert, J. 2003. Evolution of heat shock protein and immunity. DEVELOPMENTAL AND COMPARATIVE 1283 IMMUNOLOGY 27:449-464.

1284 Rodrigues, J.F., Mathias-Santos, C., Sbrogio-Almeida, M.E., Amorim, J.H., Cabrera-Crespo, J., Balan, A., and 1285 Ferreira, L.C. 2011. Functional diversity of heat-labile toxins (LT) produced by enterotoxigenic Escherichia coli: 1286 differential enzymatic and immunological activities of LT1 (hLT) AND LT4 (pLT). JOURNAL OF BIOLOGICAL 1287 CHEMISTRY 286:5222-5233. 10.1074/jbc.M110.173682

1288 Roose, K., De Baets, S., Schepens, B., and Saelens, X. 2013. Hepatitis B core-based virus-like particles to present 1289 heterologous epitopes. Expert Review of Vaccines 12:183-198. 10.1586/erv.12.150

1290 Rossi, O., Pesce, I., Giannelli, C., Aprea, S., Caboni, M., Citiulo, F., Valentini, S., Ferlenghi, I., MacLennan, C.A., 1291 D'Oro, U., Saul, A., and Gerke, C. 2014. Modulation of endotoxicity of Shigella generalized modules for membrane 1292 antigens (GMMA) by genetic lipid A modifications: relative activation of TLR4 and TLR2 pathways in different 1293 mutants. JOURNAL OF BIOLOGICAL CHEMISTRY 289:24922-24935. 10.1074/jbc.M114.566570

1294 Rueckert, C., and Guzman, C.A. 2012. Vaccines: from empirical development to rational design. PLoS Pathogens 
1295

1296

1297

1298

1299

1300

1301

1302

1303

1304

1305

1306

1307

1308

1309

1310

1311

1312

1313

1314

1315

1316

1317

1318

1319

1320

1321

1322

1323

1324

1325

1326

1327

1328

1329

1330

1331

1332

1333

1334

1335

8:e1003001. 10.1371/journal.ppat.1003001

Rueda, F., Eich, C., Cordobilla, B., Domingo, P., Acosta, G., Albericio, F., Cruz, L.J., and Domingo, J.C. 2017. Effect of TLR ligands co-encapsulated with multiepitopic antigen in nanoliposomes targeted to human DCs via Fc receptor for cancer vaccines. IMMUNOBIOLOGY 222:989-997. 10.1016/j.imbio.2017.06.002

Saadi, M., Karkhah, A., and Nouri, H.R. 2017. Development of a multi-epitope peptide vaccine inducing robust T cell responses against brucellosis using immunoinformatics based approaches. INFECTION GENETICS AND EVOLUTION 51:227-234. 10.1016/j.meegid.2017.04.009

Schmidt, J., Welsch, T., Jager, D., Muhlradt, P.F., Buchler, M.W., and Marten, A. 2007. Intratumoural injection of the toll-like receptor-2/6 agonist 'macrophage-activating lipopeptide-2' in patients with pancreatic carcinoma: a phase I/II trial. Br J Cancer 97:598-604. 10.1038/sj.bjc.6603903

Schocker, N.S., Portillo, S., Brito, C.R., Marques, A.F., Almeida, I.C., and Michael, K. 2016. Synthesis of Galalpha(1,3)Galbeta(1,4)GlcNAcalpha-, Galbeta(1,4)GlcNAcalpha- and GlcNAc-containing neoglycoproteins and their immunological evaluation in the context of Chagas disease. GLYCOBIOLOGY 26:39-50. 10.1093/glycob/cwv081

Schulze, K., Ebensen, T., Chandrudu, S., Skwarczynski, M., Toth, I., Olive, C., and Guzman, C.A. 2017. Bivalent mucosal peptide vaccines administered using the LCP carrier system stimulate protective immune responses against Streptococcus pyogenes infection. Nanomedicine 13:2463-2474. 10.1016/j.nano.2017.08.015

Seth, L., Bingham, F.K., Kaba, S.A., Musser, D.M., Emadi, S., Matyas, G.R., Beck, Z., Alving, C.R., Burkhard, P., and Lanar, D.E. 2017. Development of a self-assembling protein nanoparticle vaccine targeting Plasmodium falciparum Circumsporozoite Protein delivered in three Army Liposome Formulation adjuvants. VACCINE 35:54485454. 10.1016/j.vaccine.2017.02.040

Sharma, M., Dash, P., Sahoo, P.K., and Dixit, A. 2017. Th2-biased immune response and agglutinating antibodies generation by a chimeric protein comprising OmpC epitope (323-336) of Aeromonas hydrophila and LTB. IMMUNOLOGIC RESEARCH. 10.1007/s12026-017-8953-8

Shaw, C.A., and Starnbach, M.N. 2008. Both CD4+ and CD8+ T cells respond to antigens fused to anthrax lethal toxin. INFECTION AND IMMUNITY 76:2603-2611. 10.1128/IAI.01718-07

Shevtsov, M., and Multhoff, G. 2016. Heat Shock Protein-Peptide and HSP-Based Immunotherapies for the Treatment of Cancer. Frontiers in Immunology 7:171. 10.3389/fimmu.2016.00171

Shirbaghaee, Z., and Bolhassani, A. 2016. Different applications of virus-like particles in biology and medicine: Vaccination and delivery systems. BIOPOLYMERS 105:113-132. 10.1002/bip.22759

Simanovich, E., Brod, V., Rahat, M.M., Drazdov, E., Walter, M., Shakya, J., and Rahat, M.A. 2017. Inhibition of tumor growth and metastasis by EMMPRIN multiple antigenic peptide (MAP) vaccination is mediated by immune modulation. OncoImmunology 6:e1261778. 10.1080/2162402X.2016.1261778

Skwarczynski, M., Zaman, M., Urbani, C.N., Lin, I.C., Jia, Z., Batzloff, M.R., Good, M.F., Monteiro, M.J., and Toth, I. 2010. Polyacrylate dendrimer nanoparticles: a self-adjuvanting vaccine delivery system. Angew Chem Int Ed Engl 49:5742-5745. 10.1002/anie.201002221

Skwarczynski, M., and Toth, I. 2011a. Peptide-based subunit nanovaccines. Current Drug Delivery 8:282-289.

Skwarczynski, M., and Toth, I. 2011b. Lipid-core-peptide system for self-adjuvanting synthetic vaccine delivery. Methods Mol Biol 751:297-308. 10.1007/978-1-61779-151-2_18

Skwarczynski, M., and Toth, I. 2014. Recent advances in peptide-based subunit nanovaccines. Nanomedicine (Lond) 9:2657-2669. 10.2217/nnm.14.187 
1336 Smith, K.D., Andersen-Nissen, E., Hayashi, F., Strobe, K., Bergman, M.A., Barrett, S.L., Cookson, B.T., and Aderem,

1337 A. 2003. Toll-like receptor 5 recognizes a conserved site on flagellin required for protofilament formation and bacterial 1338 motility. NATURE IMMUNOLOGY 4:1247-1253. 10.1038/ni1011

1339 Smith, M.L., Corbo, T., Bernales, J., Lindbo, J.A., Pogue, G.P., Palmer, K.E., and McCormick, A.A. 2007. Assembly 1340 of trans-encapsidated recombinant viral vectors engineered from Tobacco mosaic virus and Semliki Forest virus and 1341 their evaluation as immunogens. VIROLOGY 358:321-333. 10.1016/j.virol.2006.08.040

1342 Strbo, N., Garcia-Soto, A., Schreiber, T.H., and Podack, E.R. 2013. Secreted heat shock protein gp96-Ig: next1343 generation vaccines for cancer and infectious diseases. IMMUNOLOGIC RESEARCH 57:311-325. 10.1007/s120261344 013-8468-X

1345 Su, Q., Yi, Y., Guo, M., Qiu, F., Jia, Z., Lu, X., Meng, Q., and Bi, S. 2013. Construction and immunological evaluation 1346 of truncated hepatitis B core particles carrying HBsAg amino acids 119-152 in the major immunodominant region 1347 (MIR). Biochem Biophys Res Commun 439:84-89. 10.1016/j.bbrc.2013.08.024

1348 Sungsuwan, S., Wu, X., and Huang, X. 2017. Evaluation of Virus-Like Particle-Based Tumor-Associated 1349 Carbohydrate Immunogen in a Mouse Tumor Model. Methods Enzymol 597:359-376. 10.1016/bs.mie.2017.06.030

1350 Suzue, K., Zhou, X., Eisen, H.N., and Young, R.A. 1997. Heat shock fusion proteins as vehicles for antigen delivery 1351 into the major histocompatibility complex class I presentation pathway. Proc Natl Acad Sci U S A 94:13146-13151.

1352 Suzue, K., and Young, R.A. 1996. Adjuvant-free hsp70 fusion protein system elicits humoral and cellular immune 1353 responses to HIV-1 p24. JOURNAL OF IMMUNOLOGY 156:873-879.

1354 Takeda, Y., Azuma, M., Funami, K., Shime, H., Matsumoto, M., and Seya, T. 2018. Type I Interferon-Independent 1355 Dendritic Cell Priming and Antitumor T Cell Activation Induced by a Mycoplasma fermentans Lipopeptide. Frontiers 1356 in Immunology 9:496. 10.3389/fimmu.2018.00496

1357 Tam, J.P. 1988. Synthetic peptide vaccine design: synthesis and properties of a high-density multiple antigenic peptide 1358 system. Proc Natl Acad Sci U S A 85:5409-5413.

1359 Tan, K., Li, R., Huang, X., and Liu, Q. 2018. Outer Membrane Vesicles: Current Status and Future Direction of These 1360 Novel Vaccine Adjuvants. Frontiers in Microbiology 9:783. 10.3389/fmicb.2018.00783

1361 Tang, D., Khaleque, M.A., Jones, E.L., Theriault, J.R., Li, C., Wong, W.H., Stevenson, M.A., and Calderwood, S.K. 1362 2005. Expression of heat shock proteins and heat shock protein messenger ribonucleic acid in human prostate 1363 carcinoma in vitro and in tumors in vivo. Cell Stress Chaperones 10:46-58.

1364 Tang, J., Yin, R., Tian, Y., Huang, Z., Shi, J., Fu, X., Wang, L., Wu, Y., Hao, F., and Ni, B. 2012. A novel self1365 assembled nanoparticle vaccine with HIV-1 Tat(4)(9)(-)(5)(7)/HPV16 E7(4)(9)(-)(5)(7) fusion peptide and GM-CSF 1366 DNA elicits potent and prolonged CD8(+) T cell-dependent anti-tumor immunity in mice. VACCINE 30:1071-1082.

1367 10.1016/j.vaccine.2011.12.029

1368 Tao, W., Hurst, B.L., Shakya, A.K., Uddin, M.J., Ingrole, R.S., Hernandez-Sanabria, M., Arya, R.P., Bimler, L., Paust, 1369 S., Tarbet, E.B., and Gill, H.S. 2017. Consensus M2e peptide conjugated to gold nanoparticles confers protection 1370 against H1N1, H3N2 and H5N1 influenza A viruses. Antiviral Res 141:62-72. 10.1016/j.antiviral.2017.01.021

1371 Therien, A., Bedard, M., Carignan, D., Rioux, G., Gauthier-Landry, L., Laliberte-Gagne, M.E., Bolduc, M., Savard, 1372 P., and Leclerc, D. 2017. A versatile papaya mosaic virus (PapMV) vaccine platform based on sortase-mediated 1373 antigen coupling. J Nanobiotechnology 15:54. 10.1186/s12951-017-0289-y

1374 Tian, M., Hua, Z., Hong, S., Zhang, Z., Liu, C., Lin, L., Chen, J., Zhang, W., Zhou, X., Zhang, F., DeFranco, A.L., 1375 and Hou, B. 2018. B Cell-Intrinsic MyD88 Signaling Promotes Initial Cell Proliferation and Differentiation To 1376 Enhance the Germinal Center Response to a Virus-like Particle. JOURNAL OF IMMUNOLOGY 200:937-948. 
1377

1378

1379

1380

1381

1382

1383

1384

1385

1386

1387

1388

1389

1390

1391

1392

1393

1394

1395

1396

1397

1398

1399

1400

1401

1402

1403

1404

1405

1406

1407

1408

1409

1410

1411

1412

1413

1414

1415

1416

1417

10.4049/jimmunol.1701067

Tobias, J., Jasinska, J., Baier, K., Kundi, M., Ede, N., Zielinski, C., and Wiedermann, U. 2017. Enhanced and long term immunogenicity of a Her-2/neu multi-epitope vaccine conjugated to the carrier CRM197 in conjunction with the adjuvant Montanide. BMC CANCER 17. 10.1186/s12885-017-3098-7

Tourani, M., Karkhah, A., and Najafi, A. 2017. Development of an epitope-based vaccine inhibiting immune cells rolling and migration against atherosclerosis using in silico approaches. COMPUTATIONAL BIOLOGY AND CHEMISTRY 70:156-163. 10.1016/j.compbiolchem.2017.08.016

Valguarnera, E., and Feldman, M.F. 2017. Glycoengineered Outer Membrane Vesicles as a Platform for Vaccine Development. Methods Enzymol 597:285-310. 10.1016/bs.mie.2017.06.032

van der Burg, S.H., Bijker, M.S., Welters, M.J., Offringa, R., and Melief, C.J. 2006. Improved peptide vaccine strategies, creating synthetic artificial infections to maximize immune efficacy. Adv Drug Deliv Rev 58:916-930. 10.1016/j.addr.2005.11.003

van der Heiden, M., Duizendstra, A., Berbers, G., Boots, A., and Buisman, A.M. 2017. Tetanus Toxoid carrier protein induced T-helper cell responses upon vaccination of middle-aged adults. VACCINE 35:5581-5588. 10.1016/j.vaccine.2017.08.056

Wang, B.Z., Gill, H.S., He, C., Ou, C., Wang, L., Wang, Y.C., Feng, H., Zhang, H., Prausnitz, M.R., and Compans, R.W. 2014. Microneedle delivery of an M2e-TLR5 ligand fusion protein to skin confers broadly cross-protective influenza immunity. JOURNAL OF CONTROLLED RELEASE 178:1-7. 10.1016/j.jconrel.2014.01.002

Wang, C., Zhu, W., Luo, Y., and Wang, B.Z. 2018. Gold nanoparticles conjugating recombinant influenza hemagglutinin trimers and flagellin enhanced mucosal cellular immunity. Nanomedicine. 10.1016/j.nano.2018.03.007 Wang, C., Zhu, W., and Wang, B.Z. 2017. Dual-linker gold nanoparticles as adjuvanting carriers for multivalent display of recombinant influenza hemagglutinin trimers and flagellin improve the immunological responses in vivo and in vitro. Int J Nanomedicine 12:4747-4762. 10.2147/IJN.S137222

Wang, H., Su, X., Zhang, P., Liang, J., Wei, H., Wan, M., Wu, X., Yu, Y., and Wang, L. 2011. Recombinant heat shock protein 65 carrying PADRE and HBV epitopes activates dendritic cells and elicits HBV-specific CTL responses. VACCINE 29:2328-2335. 10.1016/j.vaccine.2010.12.124

Wang, W., Feng, F., Lv, J., Xie, Z., Chen, J., Zhang, L., and Li, W. 2017. Major Immunodominant Region of Hepatitis B Virus Core Antigen as a Delivery Vector to Improve the Immunogenicity of the Fusion Antigen ROP2-SAG1 Multiepitope from Toxoplasma gondii in Mice. VIRAL IMMUNOLOGY 30:508-515. 10.1089/vim.2016.0135

Wang, Y., Alahdal, M., Ye, J., Jing, L., Liu, X., Chen, H., Jin, L., and Cao, R. 2018. Inhibition of RM-1 prostate carcinoma and eliciting robust immune responses in the mouse model by using VEGF-M2-GnRH3-hinge-MVP vaccine. GENES AND IMMUNITY. 10.1038/s41435-017-0005-9

Wang, Y., Kelly, C.G., Singh, M., McGowan, E.G., Carrara, A.S., Bergmeier, L.A., and Lehner, T. 2002. Stimulation of Th1-polarizing cytokines, $\mathrm{C}-\mathrm{C}$ chemokines, maturation of dendritic cells, and adjuvant function by the peptide binding fragment of heat shock protein 70. JOURNAL OF IMMUNOLOGY 169:2422-2429.

Wei, S., Lei, Y., Yang, J., Wang, X., Shu, F., Wei, X., Lin, F., Li, B., Cui, Y., Zhang, H., and Wei, S. 2018. Neutralization effects of antibody elicited by chimeric HBV S antigen viral-like particles presenting HCV neutralization epitopes. VACCINE 36:2273-2281. 10.1016/j.vaccine.2018.03.036

Wen, F., Ma, J.H., Yu, H., Yang, F.R., Huang, M., Zhou, Y.J., Li, Z.J., Wang, X.H., Li, G.X., Jiang, Y.F., Tong, W., and Tong, G.Z. 2016. A novel M2e-multiple antigenic peptide providing heterologous protection in mice. Journal of Veterinary Science 17:71-78. 10.4142/jvs.2016.17.1.71 
1418 Wesche, J., Elliott, J.L., Falnes, P.O., Olsnes, S., and Collier, R.J. 1998. Characterization of membrane translocation 1419 by anthrax protective antigen. BIOCHEMISTRY 37:15737-15746. 10.1021/bi981436i

1420 Wu, Y., Zhu, R., Xu, L., Li, Y., Li, S., Yu, H., Li, S., Zhu, H., Cheng, T., and Xia, N. 2017. A novel combined vaccine 1421 based on monochimeric VLP co-displaying multiple conserved epitopes against enterovirus 71 and varicella-zoster virus. VACCINE 35:2728-2735. 10.1016/j.vaccine.2017.03.065

1423

1424

1425

1426

1427

1428

1429

1430

1431

1432

1433

1434

1435

1436

1437

1438

1439

1440

1441

1442

1443

1444

1445

1446

1447

1448

1449

1450

1451

1452

1453

1454

1455

1456

1457

1458
$\mathrm{Xu}$, A., Zhang, L., Chen, Y., Lin, Z., and Li, R. 2017. Immunogenicity and efficacy of a rationally designed vaccine against vascular endothelial growth factor in mouse solid tumor models. Cancer Immunol Immunother 66:181-192. 10.1007/s00262-016-1928-0

Yang, L., Li, W., Kirberger, M., Liao, W., and Ren, J. 2016. Design of nanomaterial based systems for novel vaccine development. Biomater Sci 4:785-802. 10.1039/c5bm00507h

Yang, Y., Ringler, P., Muller, S.A., and Burkhard, P. 2012. Optimizing the refolding conditions of self-assembling polypeptide nanoparticles that serve as repetitive antigen display systems. JOURNAL OF STRUCTURAL BIOLOGY 177:168-176. 10.1016/j.jsb.2011.11.011

Zachova, K., Krupka, M., and Raska, M. 2016. Antigen Cross-Presentation and Heat Shock Protein-Based Vaccines. Arch Immunol Ther Exp (Warsz) 64:1-18. 10.1007/s00005-015-0370-x

Zaman, M., Abdel-Aal, A.B., Fujita, Y., Phillipps, K.S., Batzloff, M.R., Good, M.F., and Toth, I. 2012. Immunological evaluation of lipopeptide group A streptococcus (GAS) vaccine: structure-activity relationship. PLoS One 7:e30146. 10.1371/journal.pone.0030146

Zaman, M., Skwarczynski, M., Malcolm, J.M., Urbani, C.N., Jia, Z., Batzloff, M.R., Good, M.F., Monteiro, M.J., and Toth, I. 2011. Self-adjuvanting polyacrylic nanoparticulate delivery system for group A streptococcus (GAS) vaccine. Nanomedicine 7:168-173. 10.1016/j.nano.2010.10.002

Zaman, M., and Toth, I. 2013. Immunostimulation by synthetic lipopeptide-based vaccine candidates: structureactivity relationships. Frontiers in Immunology 4:318. 10.3389/fimmu.2013.00318

Zhai, L., Peabody, J., Pang, Y.S., Schiller, J., Chackerian, B., and Tumban, E. 2017. A novel candidate HPV vaccine: MS2 phage VLP displaying a tandem HPV L2 peptide offers similar protection in mice to Gardasil-9. Antiviral Res 147:116-123. 10.1016/j.antiviral.2017.09.012

Zhang, L., Wang, J., Xu, A., Zhong, C., Lu, W., Deng, L., and Li, R. 2016. A Rationally Designed TNF-alpha EpitopeScaffold Immunogen Induces Sustained Antibody Response and Alleviates Collagen-Induced Arthritis in Mice. PLoS One 11:e163080. 10.1371/journal.pone.0163080

Zhao, X., Chen, L., Luckanagul, J.A., Zhang, X., Lin, Y., and Wang, Q. 2015. Enhancing Antibody Response against Small Molecular Hapten with Tobacco Mosaic Virus as a Polyvalent Carrier. CHEMBIOCHEM 16:1279-1283. 10.1002/cbic. 201500028

Zheng, D., Chen, S., Qu, D., Chen, J., Wang, F., Zhang, R., and Chen, Z. 2016. Influenza H7N9 LAH-HBc virus-like particle vaccine with adjuvant protects mice against homologous and heterologous influenza viruses. VACCINE 34:6464-6471. 10.1016/j.vaccine.2016.11.026

Zhu, Q., Egelston, C., Gagnon, S., Sui, Y., Belyakov, I.M., Klinman, D.M., and Berzofsky, J.A. 2010. Using 3 TLR ligands as a combination adjuvant induces qualitative changes in $\mathrm{T}$ cell responses needed for antiviral protection in mice. JOURNAL OF CLINICAL INVESTIGATION 120:607-616. 10.1172/JCI39293

Zhu, R., Liu, J., Chen, C., Ye, X., Xu, L., Wang, W., Zhao, Q., Zhu, H., Cheng, T., and Xia, N. 2016. A highly conserved epitope-vaccine candidate against varicella-zoster virus induces neutralizing antibodies in mice. $V A C C I N E$ 34:1589-1596. 10.1016/j.vaccine.2016.02.007 


\section{Figure 1}

The basic process of immune response in vivo.

The antigen is ingested and processed by immature antigen -presenting cells (e,g.,DCs), APCs becomes mature under the action of immune-stimulating molecules. Mature APCs can express antigen information on its surface in the form of antigen peptide -MHC molecular complex and present it to $T$ cells. After recognizing this complex, $T$ cells are activated, proliferated, and differentiated into different subtypes of effector T cells (CD4+ and CD8+) to participate in the regulation of antigen-specific humoral and cellular immune responses.

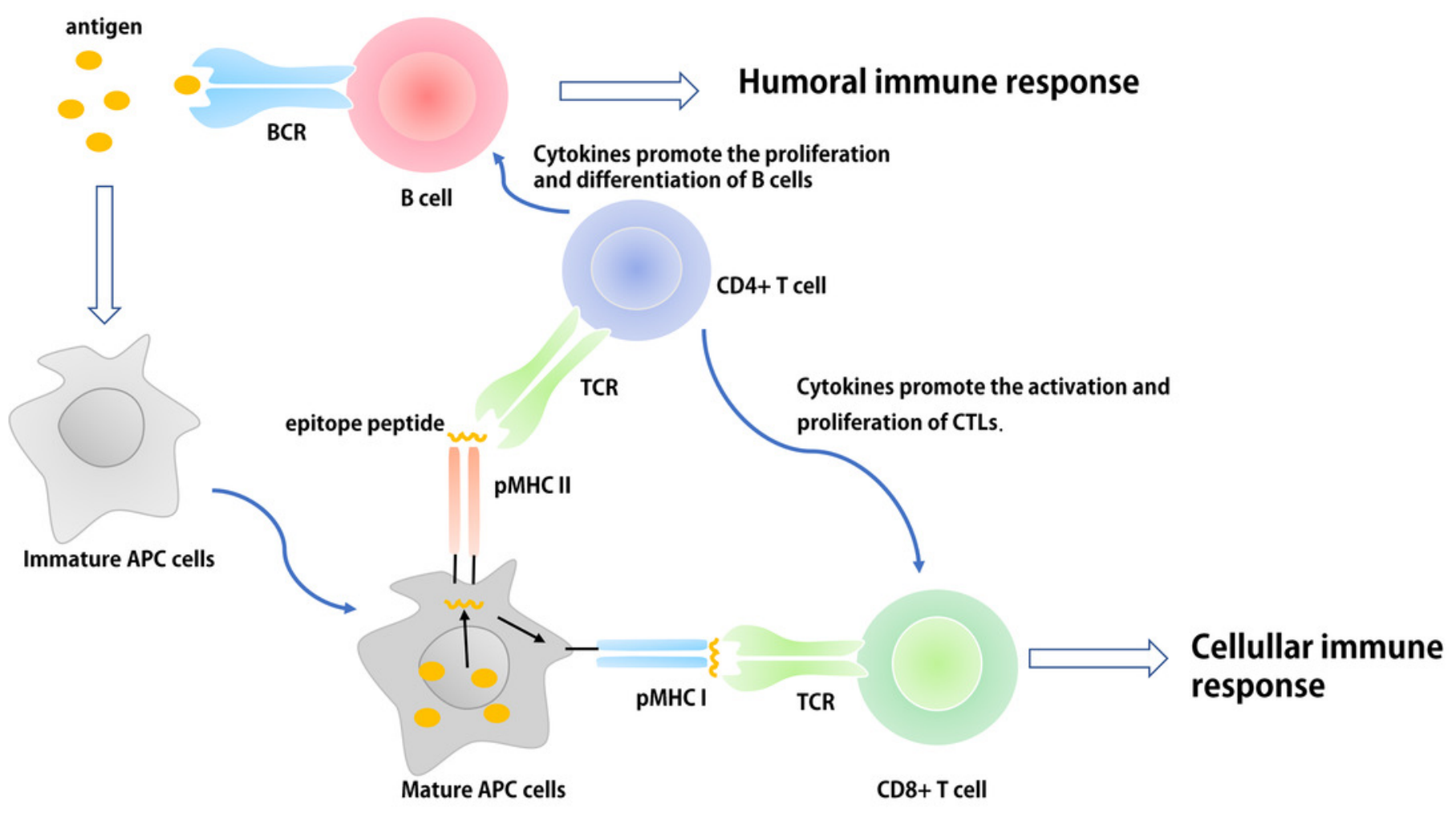




\section{Figure 2}

The signaling pathways of TLRs.

The extracellular parts of TLRs are activated after binding with ligands, and the conformation changes lead to convergence of downstream molecules, which triggers the signaling pathway and induced the up-regulation and activation of cytokines, chemokines and other co-stimulatory factors. With the exception of TLR3, all TLRs initiate MyD88 through the expressed MyD88 or simultaneous bridging MAL, and then activate the NF-kB and MAPK through tandem reactions, which induces the production of pro-inflammatory cytokines such as IL-1, IL-6, TNF- $\alpha$, etc. The overexpression of both TRIF and TRAM or TRIF alone initiated the TRIF dependent pathway, the TRIF dependent pathway activates IFN regulatory factors and mediates the production of type I IFNs. In addition, the activation of TLR4 is related to both pathways.

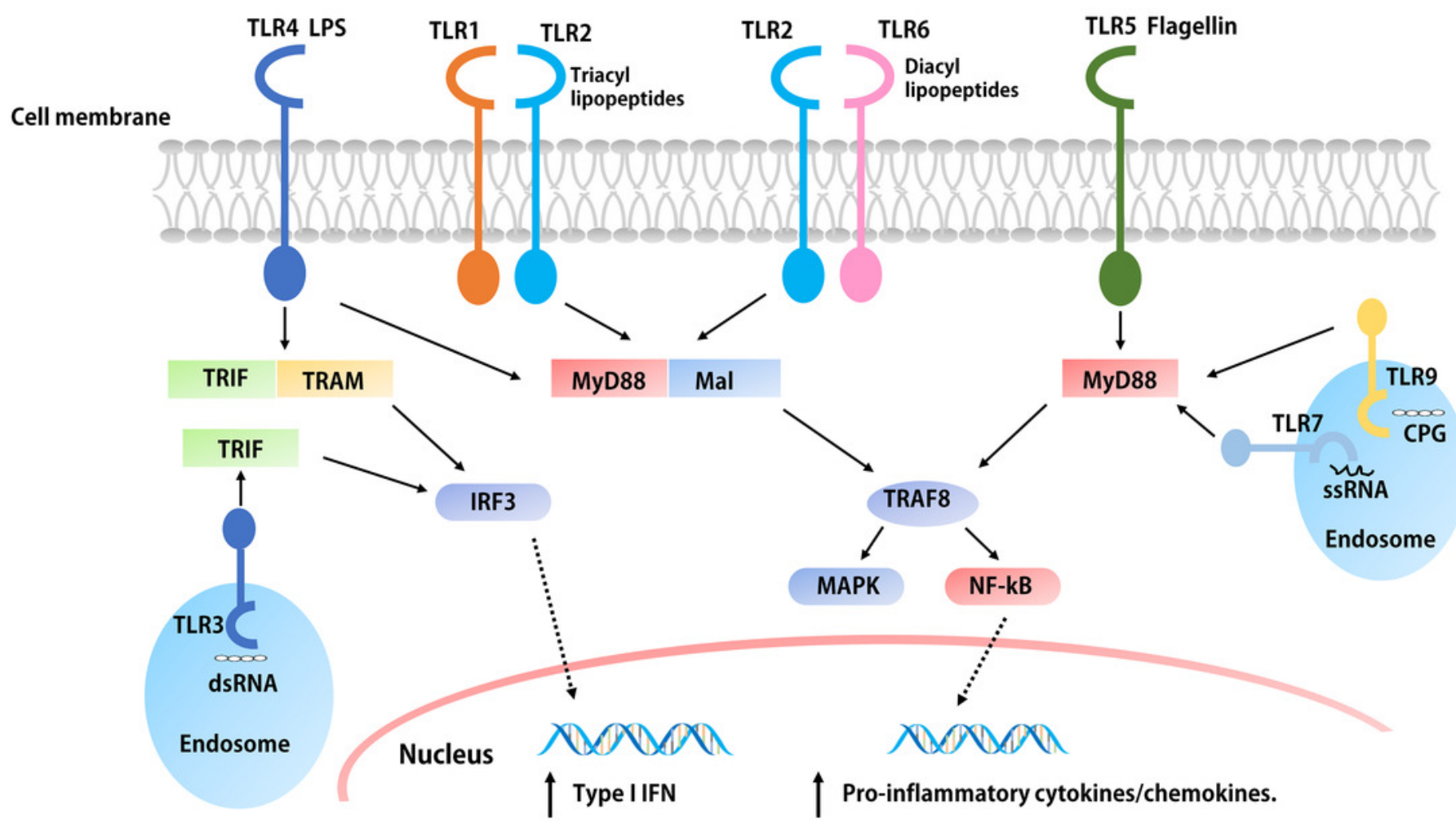




\section{Figure 3}

The chemical structures of different TLR2-targeting Pam lipopeptides .

(A) Pam2Cys and Pam3Cys lipopeptides. (B) MALP2 and FSL-1 lipopeptides. (C) Pam2CSK4 and Pam3CSK4 lipopeptides.

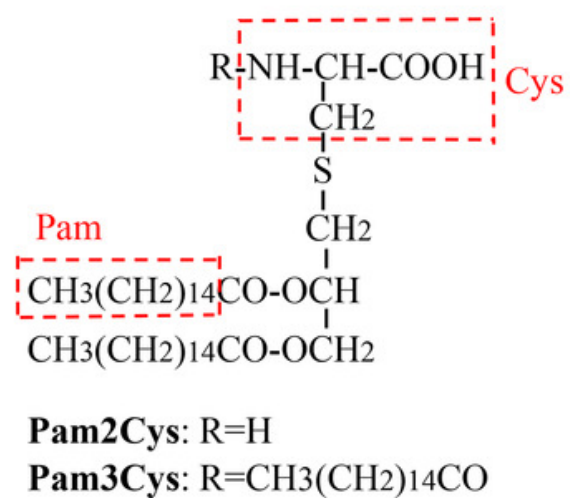

(A)

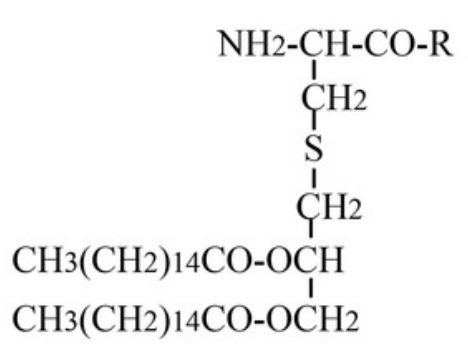

MALP2: $\mathrm{R}=$ GNNDESNISFKEK FSL-1: $\mathrm{R}=$ GDPKHPKSF

(B)

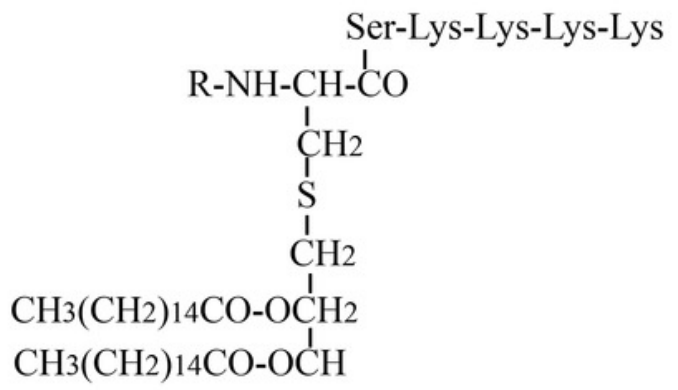

Pam2CSK4: $\mathrm{R}=\mathrm{H}$

Pam3CSK4: $\mathrm{R}=\mathrm{CH} 3(\mathrm{CH} 2) 14 \mathrm{CO}$

(C) 


\section{Figure 4}

Recombinant HBc-based VLPs or HBs-based VLPs.

(A):1) The HBC proteins naturally form the dimers, the building blocks that forms the VLPs. It takes about 60 such dimers (i.e., 120 copies of HBC) to form a HBc-based VLP. The results showed that there were about 40 amino acid residues inserted into the $\mathrm{N}$-terminal of $\mathrm{HBC}$. In the MIR region of $\mathrm{HBC}, 50$ or 100 amino acid residues can be inserted, and as many as 100 or more residues at the $\mathrm{C}$-terminal do not interfere with the formation of particles. 2) Hepatitis B surface antigen ( $\mathrm{HBsAg}$ ) can also self-assemble into highly organized viroid particles with a diameter of $22 \mathrm{~nm}$. These HBs-derived VLPs contain about $100 \mathrm{HBsAg}$ molecules and provide a unique opportunity to display multiple exogenous epitopes. (B): Hepatitis B virus tandem core platform. The two replicas of HBc protein are linked together by covalent bonds through flexible amino acid sequences so that the fused dimers can be folded correctly and assembled into HBC particles. In the assembled HBC particles, the four helix bundles formed at each dimer interface appear on the surface as prominent "spikes". The tip of the spike is the preferred site for inserting foreign sequences for bivalent vaccine. 
(A)
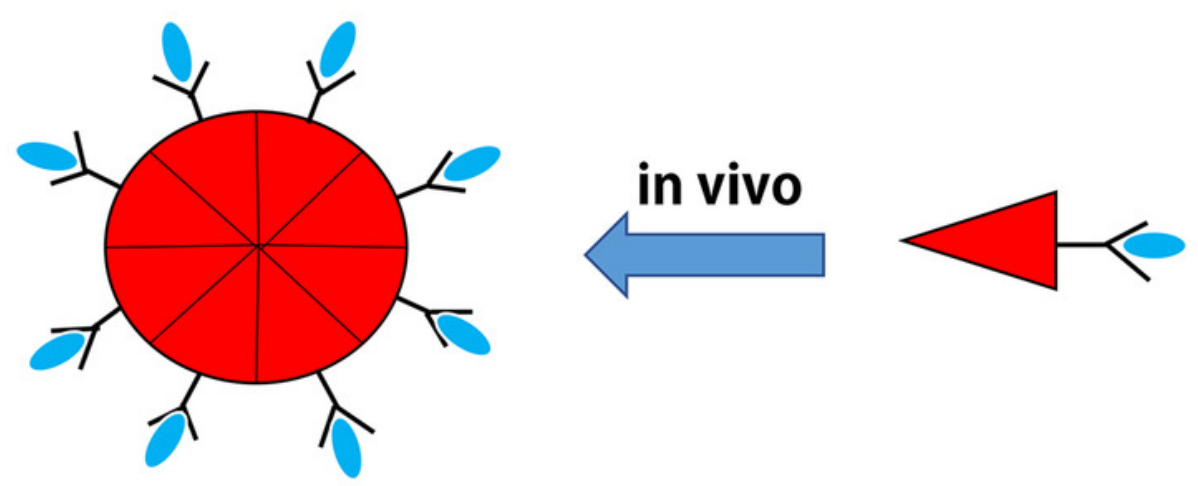

$$
\checkmark \prec \begin{aligned}
& \mathrm{HBc} / \mathrm{HBs} \text { antigen } \\
& \text { epitope/s }
\end{aligned}
$$

(B)
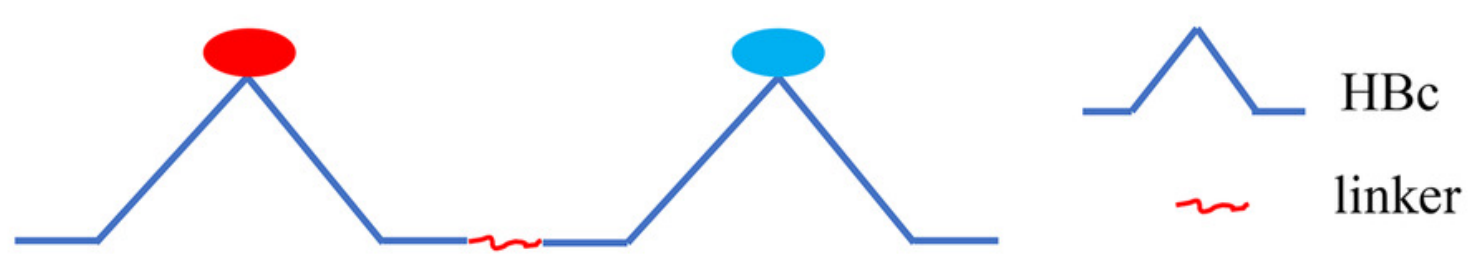

epitope/s 


\section{Figure 5}

The schematic diagram of MAP system and LCP nanoparticles.

(A) MAP epitope vaccine based on lysine scaffold. (B) The LCP nanoparticles.

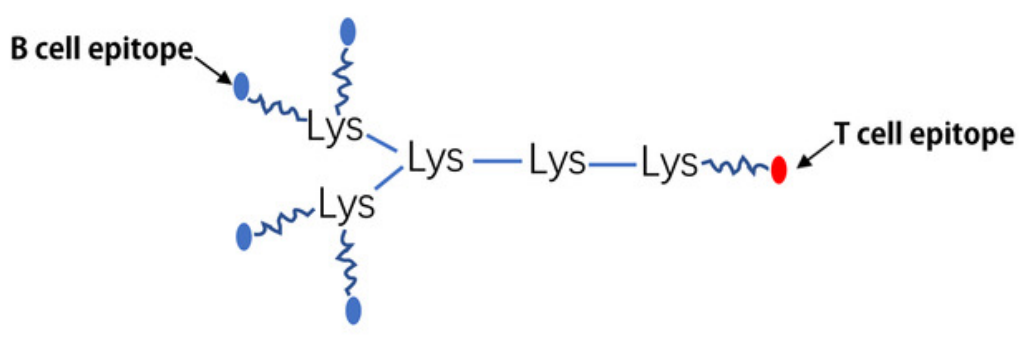

(A)

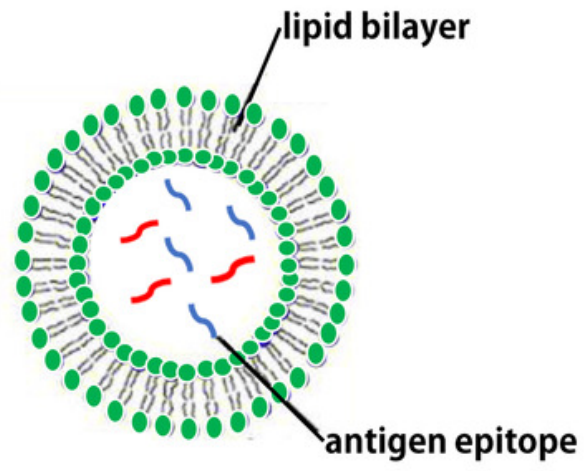

(B) 
Figure 6

Self-assembled peptides nanoparticles ( SAPNs ).

Systematic self-assembling peptides ( $\beta$-sheet nanofiber vaccine) with antigen epitopes.
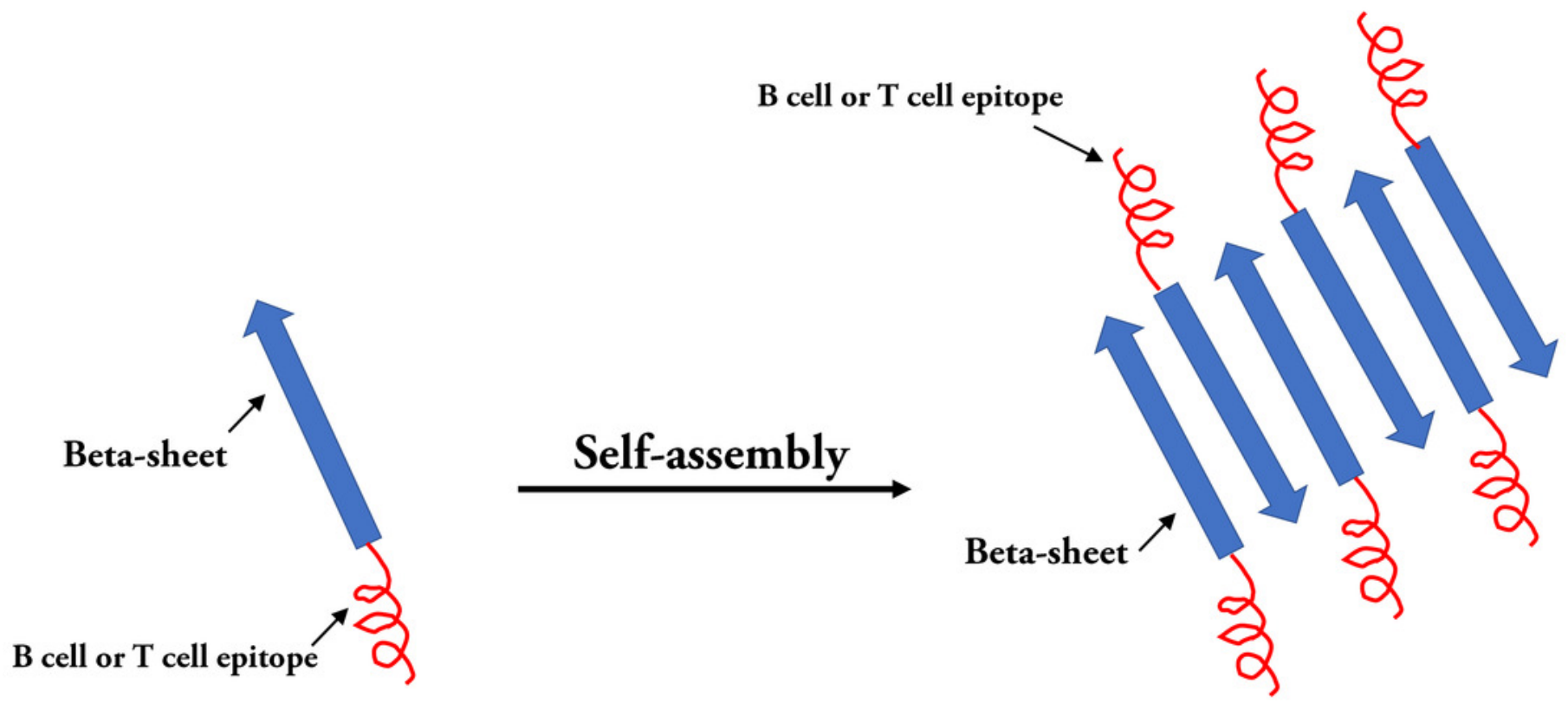
Figure 7

The inorganic nanoparticles.

The formation of gold nanoparticles carrying antigen epitopes.

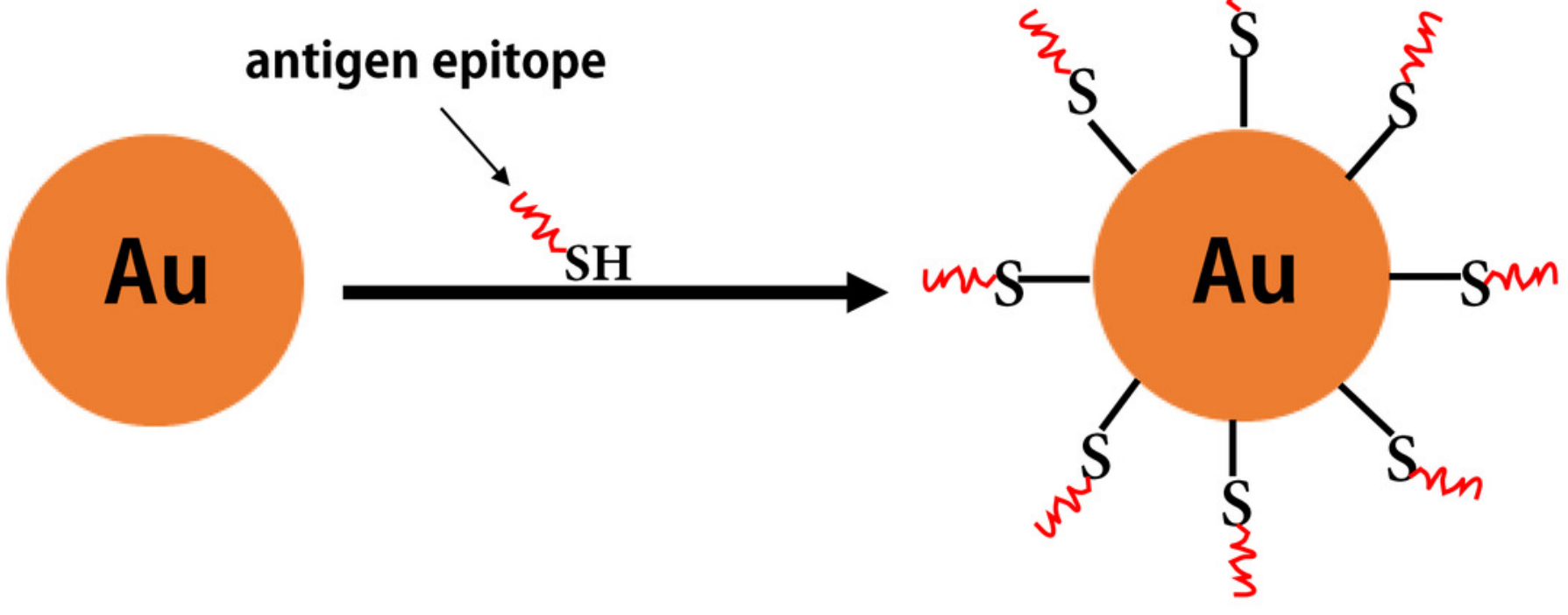




\section{Table $\mathbf{1}$ (on next page) \\ Different subtypes of TLRs and their identified PAMPs.}

The biological activities of TLRs agonists that can activate the immune system. 
1

TLRs

TLR2/TLR6

TLR2/TLR1

(1)

TLR4

Lipopolysaccharides(LPS)、 Heat shock

(HSP)、 $\beta$-defensin、 Heparin-binding

The lipoproteins of bacteria or mycoplasma.

Lipopeptide (MALP-2)、 Peptidoglycan (PGN)

hemagglutinin(HBHA)

TLR5

TLR3

Double-stranded RNA (ds RNA)、 Poly(I:C)

Gram-negative bacteria flagellin

TLR7/TLR8

Single-stranded RNA (ssRNA)

TLR9

CpG DNA、Hemozoin、 Herpes simplex virus DNA
Biological activity

Activate intracellular signal NF-KB, induce adhesion molecules and inflammatory cytokines.

protein Induce the expression of adhesion molecules and inflammatory cytokines

Reed et al., 2016;

Kaisho \& Akira, 2002)

The potent proinflammatory activity by inducing NF-KB activation, and expression of IL- 8 and inducible NO synthase in intestinal epithelial cells Induce IL-12 production and DC maturation and elevate CD40 expression on APCs.

(Kaisho \& Akira, 2002;

Induce the expression of adhesion molecules and

(Vasilakos \& Tomai, 2013) inflammatory cytokines

Production of Th1 cytokines and promotion of cytotoxic activity of NK cells.
Cheng et al., 2018)

(Kaisho \& Akira, 2002;

Moyle, 2017)

(Zhu et al., 2010;

Kaisho \& Akira, 2002) 


\section{Table 2 (on next page)}

Various lipopeptides that can be used as build-in adjuvants.

The biological activities or structures of various lipopeptides and their natural analogues. 


\begin{tabular}{|c|c|c|c|}
\hline Name & Natural analogues. & Biological activity or structure. & References \\
\hline MALP2 & the M161Ag lipoprotein of Mycoplasma fermentans & $\begin{array}{l}\text { The agonistic ligand of the TLR } 2 / 6 \text { heterodimer } \\
\text { Induces production of inflammatory cytokines from } \\
\text { macrophages, monocytes and DCs. } \\
\text { MALP2s, a short form of MALP2, lacks the last eight amino } \\
\text { acids of the full length MALP2 (Pam2- } \\
\text { CGNNDESNISFKEK). As an adjuvant capable of inducing } \\
\text { DC maturation, MALP2s can be used in antitumor } \\
\text { immunotherapy }\end{array}$ & $\begin{array}{l}\text { (Takeda et al., } \\
\text { 2018; McDonald } \\
\text { et al., 2014) }\end{array}$ \\
\hline FSL-1 & the LP44 lipoprotein from Mycoplasma salivarium & $\begin{array}{l}\text { FSL-1 (Pam2CGDPKHPKSF) contains the structure of } \\
\text { diacylglycerol similar to Pam2CSK4, which play a key role in } \\
\text { immune cell maturation and Th2 immunization and induces } \\
\text { the expression of inflammatory cytokines, such as monocyte } \\
\text { chemotactic protein (MCP)-1, IL-6, IL-8 and tumor necrosis } \\
\text { factor (TNF)- } \alpha \text { by monocytes/macrophages. }\end{array}$ & $\begin{array}{l}\text { (Liu et al., 2016; } \\
\text { Kurkjian et al., } \\
\text { 2017) }\end{array}$ \\
\hline Pam3CSK4 & The Braun lipoprotein in Escherichia coli & $\begin{array}{l}\text { Pam3CSK } 4 \text { is the first mimicking lipopeptide that contains } \\
\text { three highly lipophilic tails and six amino acids and can } \\
\text { activates the TLR } 2 / 1 \text { signaling pathway. }\end{array}$ & $\begin{array}{l}\text { (Basto \& Leitao, } \\
\text { 2014; Arai et al., } \\
\text { 2018) }\end{array}$ \\
\hline Pam2CSK4 & The LP44 lipoprotein from Mycoplasma salivarium & $\begin{array}{l}\text { The palmityl tail on the N-terminal of cysteine of Pam3CSK } 4 \\
\text { has been shown to be an dispensable part of TLR2 activation. } \\
\text { Removing this lipophilic tail forms a highly effective } \\
\text { Pam2CSK4. }\end{array}$ & $\begin{array}{l}\text { (Halliday et al., } \\
\text { 2016; Arai et al., } \\
\text { 2018) }\end{array}$ \\
\hline Pam3Cys & The Braun lipoprotein in Escherichia coli & $\begin{array}{l}\text { Modulation of APC Migration and Antigen Internalization. } \\
\text { More efficient than CpG and resiquimod (TLR9 andTLR7/8 } \\
\text { ligands) } \\
\text { The enantiopure Pam3Cys derivatives that contained R- } \\
\text { configured glycerol can induce cytokines and antibody } \\
\text { production in mice when administered with antigens. The } \\
\text { antigen-specific CTL cells induced by S-epimers were } \\
\text { significantly higher in mice. Vaccines containing Pam3Cys }\end{array}$ & $\begin{array}{l}\text { (Zaman \& Toth, } \\
\text { 2013; McDonald } \\
\text { et al., 2015) }\end{array}$ \\
\hline
\end{tabular}


can reduce the burden of breast tumors in mice and induce the production of CTLs.

Pam2Cys Cytoplasmic membrane of Mycoplasma fermentans
Compared with Pam3Cys, Pam2Cys have higher solubility characteristics and is a more potential stimulus factor splenocytes and macrophages. The activity of the natural $\mathrm{R}$ isomer of Pam2Cys is 100 times that of $\mathrm{S}$ isomer. Dependent on the palm acylated cysteine lipid head group activates downstream signals and activate TLR2 on DC's and trigger maturation of DCs
(Zaman \& Toth, 2013; Nalla et

al., 2015)

.




\section{Table 3(on next page)}

Several major types of heat shock proteins.

The intracellular localizations and biological functions of several major types of heat shock proteins. 
2

HSP
Intracellular localization
Biological function

References

family/members

$\begin{array}{llll}\text { HSP60/HSP58、 } & \text { Mitochondrion } & \text { It plays a role in the folding of proteins in the mitochondrial matrix. } & \text { (Juwono \& Martinus, } \\ \text { HSP60、 HSP65 } & \text { cytoplasm } & \text { Hsp60 can affect T cell response in two ways: as a ligand of toll-like } & 2016 ; \\ & & \text { receptor } 2 \text { signalling and as an antigen. } & \text { 2018) }\end{array}$

HSP70/HSP68、 Cytoplasm or nucleus

HSP70、HSP72、 Mitochondrion

HSP73

HSP90/HSP83、 Cytoplasm or nucleus

HSP84、HSP87、 Endoplasmic reticulum

HSP90、Gp96

HSP110

Small HSPs/HSP22

HSP23、HSP26、 HSP27、 HSP28, $\alpha \beta$-crystallin
Golgiosome

Cytoplasm or nucleus

Cytoplasm or nucleus

Mitochondrion

Heme catabolism or antioxygenic property

Actin dynamics presenting ability of APC.
(Craig, 2018; Cheng et al., 2014)

(Pearl et al., 2008; Strbo et al., 2013) pathways and cell cycle processes, and plays an important role in carcinogenic signal transduction, anti-apoptosis, metastasis, stress injury, autoimmune and other diseases treatment. HSP90 can promote the correct assembly, folding, or restoring the normal conformation of the damaged protein, prevent the wrong folding and aggregation of the protein and also promote the processing of MHC I antigen through the generation and assembly of the antigen determinant cluster of 26 s protease complex.

HSP110 has a strong molecular chaperone function and can present antigen peptides to APCs to activate specific antitumor cellular immunity. (Tang et al., 2005; Ding et al., 2013) and costimulatory molecules of APC, thus enhancing the antigen-

(Bolhassani \& Rafati, 2008) 


\section{Table 4(on next page)}

Summary of several bacterial toxin build-in adjuvants listed in this paper.

The advantages and characteristics and some application examples of several bacterial toxin build-in adjuvants. 
2

\section{Objective}

Heat labile toxins (HLT)
Advantages and Characteristics

(1)B subunit of LT or the mutant form of LT can activate the dendritic cells and $\mathrm{B}$ and $\mathrm{T}$ lymphocytes.

Cholera toxin (1)CTB's strong affinity to GM1 ganglioside (CT) receptor.

(2)Reduce the minimum concentration of antigens required for activation of immune cells.

Diphtheria (1)CRM197 is a mutant of DT, which can toxin(DT) effectively combine and present peptides and rapidly activate CD4 T cells by multiplicity of Th1 and Th2 cytokines.

(2)The DTT is no safety hazard and contains four Th cell epitopes.

(3)DTT can form a turn-helix-turn structure completely exposed to the surface, which may be a potential site for insertion of exogenous epitopes.

Tetanus toxoid (1)TT has multiple CD4+ Th cell epitopes and (TT) associated memory Th subsets.

(2)Helper epitopes selected from Tetanus toxin fragment C (TTFrC).

Anthrax toxin (1)The N-terminal (the first 255 amino acids) of lethal factor (LF) of anthrax toxin termed LFn, retains protective antigen (PA)-binding and translocation capabilities but has no toxic activity. (2)LFn has been used to transfer foreign proteins and peptides into the cytoplasm
(1)A multivalent epitope-based vaccine CWAE against h. (Guo et al., 2017; pylori and anti-atherosclerosis multi-epitope vaccine.

(2)CTB-Human Mucin 1(MUC1) vaccine.

Tourani et al., 2017)

(1)Several short B cell epitopes on the Her-2/neu protein were (Tobias et al., coupled with CRM197.

2017; Zhang et

(2)The epitope of TNF- $\alpha$ is coupled to the insertion site of DTT, developed an anti TNF- $\alpha$ vaccine DTNF.

al., 2016; Zhang

et al., 2016)

(Saadi et al., 2017; Broker, 2016; Arcuri et al., 2017)

(1)A chicken ovalbumin (Ova) recombinant protein (LFn- (Wesche et al., Ova). 1998; Shaw \& Starnbach, 2008; Chandra et al., 2006 ) 


\section{Table 5 (on next page)}

Different investigational built-in adjuvants for epitope-based vaccines.

The clinical phases of various built-in adjuvants and their applications in the treatment of different diseases. 
1

Build-in adjuvant

Gp96

HSP70

Bacterial flagellin

MALP-2

$\mathrm{HBcAg}$

Q $\beta$ VLP

SAPNs

\section{Bacterial diarrhea and \\ Guillain-Barré syndrome \\ Influenza A virus}

Dengue viruses/ Zika virus

Respiratory syncytial virus

Pancreatic cancer

$$
\begin{gathered}
\text { P. falciparum } \\
\text { Influenza A virus }
\end{gathered}
$$

Hepatitis B virus

Melanoma

Persistent allergic asthma

Hypertension

Nicotine dependence

Alzheimer's disease

$$
\text { Hepatitis B }
$$

Cervix cancer

Parvovirus porcine infection

Influenza A

Malaria

Alzheimer's disease

Malignant melanoma
Clinical phase

Pilot

Phase I

Phase I

Phase I

Phase I

Phase I-II

Phase I

Phase I

Pilot

Phase I

Phase I

Phase I

Phase I/II

Preclinical

Preclinical

Phase I/II

Phase I

Phase I

Licensed

Phase I \& II, IIa

Phase II

Phase I

Phase I

Phase I/ IIa

Phase III

Phase III

Phase I/II

Phase I/II

Phase III

Phase II

Phase II
References

(Shevtsov \& Multhoff, 2016)

(Mazzaferro et al., 2003)

(Shevtsov \& Multhoff, 2016)

(Maki et al., 2007)

(Shevtsov \& Multhoff, 2016)

(Bloch \& Parsa, 2014)

(Shevtsov \& Multhoff, 2016)

(Shevtsov \& Multhoff, 2016)

(Guzhova et al., 2013)

(Guzhova et al., 2013)

(SenGupta et al., 2004)

(Moyle, 2017)

(Taylor et al., 2011; Taylor et al., 2012)

(Liu et al., 2015)

(Liu et al., 2015)

(Schmidt et al., 2007)

(Roose et al., 2013)

(Roose et al., 2013)

(Effio \& Hubbuch, 2015)

(Goldinger et al., 2012)

(Beeh et al., 2013)

(Ambuhl et al., 2007)

(Cornuz et al., 2008)

(Winblad et al., 2012)

(Shirbaghaee \& Bolhassani, 2016a)

(Shirbaghaee \& Bolhassani, 2016a)

(Kushnir et al., 2012)

(Kushnir et al., 2012)

(Kushnir et al., 2012)

(Lopez-Sagaseta et al., 2016)

(Lopez-Sagaseta et al., 2016) 
Liposome

Chitosan

Gold nanoparticle

PLGA
Influenza

Streptococcus mutans

Neisseria meningitides

HIV

Mycobacterium

tuberculosis

RSV

Tuberculosis

Allergy

Influenza

HIV

RSV

Foot-and-mouth disease

Malaria
Phase I/II

Phase I

Phase I

Phase I

Phase I

Clinical trial

Phase I

Preclinical

Phase II/III

Preclinical

Preclinical

Preclinical

Preclinical

Clinical trial

Clinical trial

Clinical trial

Clinical trial

Clinical trial
(Tandrup et al., 2016)

(Tandrup et al., 2016)

(Tandrup et al., 2016)

(Tandrup et al., 2016)

(Tandrup et al., 2016)

(Yang et al., 2016)

(Bolhassani et al., 2014)

(Bolhassani et al., 2014)

(Bolhassani et al., 2014)

(Bolhassani et al., 2014)

(Bolhassani et al., 2014)

(Bolhassani et al., 2014)

(Bolhassani et al., 2014)

(Vartak \& Sucheck, 2016; Zhao et al., 2014)

(Vartak \& Sucheck, 2016; Zhao et al., 2014)

(Vartak \& Sucheck, 2016; Zhao et al., 2014)

(Vartak \& Sucheck, 2016; Zhao et al., 2014)

(Vartak \& Sucheck, 2016; Zhao et al., 2014) 